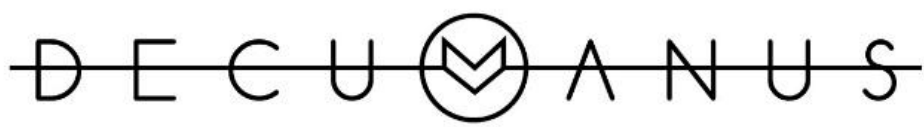

\title{
ARQUITECTURA “IN-CONTENIBLE” Y EL ESPACIO INDECIBLE. LA DIMENSIÓN ÓNTICA DEL ESPACIO LECORBUSIANO
}

IRREPRESSIBLE ARCHITECTURE AND UNSPEAKABLE SPACE. THE ONTOLOGICAL DIMENSION OF LECOBUSIER'S SPACE.

\author{
Valentina Mejía Amézquita \\ Vinculación \\ Universidad de Caldas, Colombia \\ E-mail: valentinamejiaamezquita@gmail.com \\ Primera versión recibida en: 03 de enero, 2016 \\ Última versión recibida en: 15 de julio, 2016
}

\section{Resumen}

El presente artículo es resultado de una investigación de largo aliento que permitió, en mi rol de arquitecto volverme sobre mi disciplina con otros ojos, los de la filosofía en un proceso de formación posgradual, orientando mi tesis al estudio a la apuesta humanista que reside, para algunos tal vez subrepticia, en modernidad arquitectónica lecorbusiana. La investigación en su integralidad se ocupó del constructo teórico, desde esta perspectiva, que determinaría su ascenso vertiginoso y, porque no, también su agotamiento.

A un siglo de dicha exposición discursiva sigue siendo legítimo hablar de ella, no para reivindicar lo que por definición podría entenderse agotado, pero si para dar su merecido lugar a uno de los aspectos más trascendentes y menos discutidos alrededor del cual giró con particular relevancia dicha modernidad y tendría profundo sentido actualmente: el espacio.

Aunque llama la atención que en el texto manifiesto Vers une Architecture de Le Corbusier que ha servido de guía cientos de investigaciones y, en particular a la nuestra, no se encuentre un capítulo o un apartado particular dedicado exclusivamente al tema, la preocupación por el mismo emerge dejando entrever las distintas posturas que sobre el mismo desarrollaría nuestro autor; reflexión que, de hecho, se remonta a sus primeros años como pintor y se agudiza en los años siguientes en su vida como arquitecto de entre guerras y postguerra hasta cristalizar una de sus más agudas disquisiciones lo que llamaría el espacio inefable texto que paradójicamente no lograría ser recordado como sus otros textos apodícticos.

En este sentido, el hilo que teje las siguientes páginas espera develar como la reflexión ontológica por el espacio es la apuesta que subyacía inherente a la arquitectura moderna en su búsqueda por trascender la tradición hasta convertirse en un proyecto civilizatorio con lo cual, 


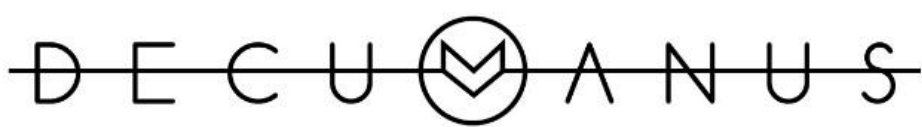

REVISTA INTERDISCIPLINARIA SOBRE ESTUDIOS URBANOS
Núm. 1 Vol. 1. Octubre 2015 - Octubre 2016

Instituto de Arquitectura, Diseño y Arte

Universidad Autónoma de Ciudad Juárez

ISSN: 2448-900X

entonces, dar cuerpo a la dimensión teórica del espacio fue la función ulterior de una práctica llamada a aportar un amplio abanico de posibilidades en relación a la búsqueda por otra manera de habitar.

Palabras clave: Espacio-tiempo, filosofía del habitar, Le Corbusier, modernidad arquitectónica, proyectar

\section{Abstract}

This article is the result of a long-term research that allowed me in my role as architect turn myself about my discipline with other eyes, those of philosophy in a process of posgradual training, directing my thesis to study the humanistic bet that resides, such surreptitious for someone, in time of the Lecorbusian architectural modernity. The research in its entirety dealt with the theoretical construct, from this perspective, that would determine its vertiginous rise and why not also his exhaustion.

A century of this discursive exposition is still legitimate to talk about it, not for claiming what by definition could be depleted, but to give their deserved place to one of the aspects more transcendent and less discussed around which it revolved with particular relevance tells by modernity and will have a profound sense now: the space.

Although it is interesting that the manifesto Vers une Architecture of LeCorbusier who has guided hundreds of investigations and in particular ours, there is any chapter or section especially dedicated exclusively to the topic, the concern by the same emerges leaving glimpse of the different postures that on the same would develop our author; reflection that, in fact goes back to his early years as painter and is acute in the following years in his life as an architect of war and post-war until crystallize one of his sharpest disquisitions which would call the ineffable space, text that paradoxically wouldn't be remembered like his other apodictic text.

Therefore, the thread that weaves the following pages expected to reveal how the ontological reflection by the space is the underlying inherent bet to modern architecture in his quest to transcend the tradition to become a civilization project, then, to give body to the theoretical dimension of space, was the further function of a so-called practice to provide a wide range of possibilities in relation to the search for another way of living.

Keywords: space-time, philosophy of living, Le Corbusier, modern architecture, project

\section{Sumario}

- Introducción

- Arquitectura Incontenible

- Reflexión Final

- Bibliografía 


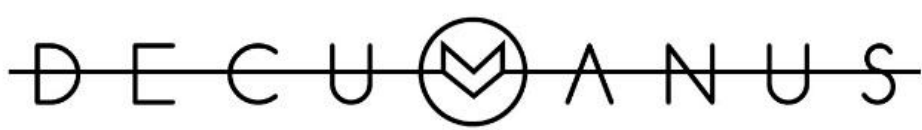

REVISTA INTERDISCIPLINARIA SOBRE ESTUDIOS URBANOS

\section{Introducción}

Cuando suena la hora de construir la casa, no es la hora del albañil ni del técnico, es la hora en la cual todo hombre hace al menos un poema en su vida. Le Corbusier, Hacia una Arquitectura, (1930[1998])

Vamos a dar por sentado que algunas de las preocupaciones alrededor de las cuales giró la discusión arquitectónica sobre la modernidad lecorbusiana han sido ya claramente comprendidas, más aún cuando pasado un siglo, se las puede mirar desde la distancia. Nuestra investigación sobre la modernidad arquitectónica se ha detenido en dar una mirada desde la filosofía, al quehacer proyectual del movimiento moderno en manos de su mayor exponente: Le Corbusier. La pesquisa se ha centrado en superar los argumentos comúnmente conocidos que han señalado a dicho movimiento de formalista, en algunos casos, de triste funcionalista, en otros, o de mero estilo, en los más severos, para ocuparse de él como una apuesta revolucionaria que en su ontología se propuso ser un renovado proyecto de mundo.

En otros resultados de este proceso investigativo hemos puesto en conocimiento que los grandes relatos, a la manera de Lyotard (1984), o los manifiestos sobre los cuales se fundó aquella modernidad tuvieron como gran propósito legitimar la práctica social de la arquitectura del denominado Movimiento Moderno en una idea por conseguir, en un futuro por realizar, de ahí que hayamos optado por concebirlo como un proyecto (Aicher, 1994); en este sentido, estaría el proyectarse "hacia una arquitectura", parafraseando al mismo Le Corbusier (1930), como una apuesta por concebir un mundo nuevo guiado por la racionalidad, la libertad y la autonomía del hombre moderno, según señala Banham (1985).

De otro lado, podemos señalar como uno de sus propósitos más sentidos la búsqueda de la belleza, no como una simple expresión formal, sino como una correspondencia entre la idea y la manifestación externa del carácter esencial que subyace en el edificio, en virtud de la posible y necesaria materialización de su profundidad óntica (Collins, 1998) y, por último, podemos mencionar la noción de funcionalidad otra referida a una condición posibilitante que describió a la arquitectura moderna como una creación del intelecto y un escenario en el que el hombre se despliega plenamente (Compagnon, 1993).

El presente artículo, entonces, se centra en mostrar el problema del espacio desde la noción racional y geométrica que acompañó los primeros años de la praxis pictórica de Le Corbusier, su ulterior trascendencia al ámbito de la arquitectura purista de sus inicios, hasta la reconfiguración del 


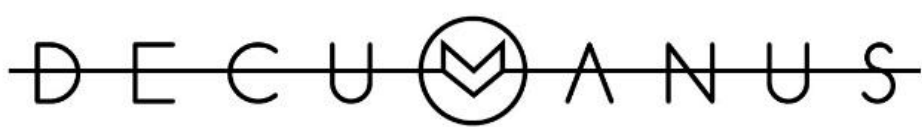

REVISTA INTERDISCIPLINARIA SOBRE ESTUDIOS URBANOS
Núm. 1 Vol. 1. Octubre 2015 - Octubre 2016

Instituto de Arquitectura, Diseño y Arte

Universidad Autónoma de Ciudad Juárez

ISSN: 2448-900X

anti-espacio o el espacio-tiempo que Le Corbusier prefería llamar el "indecible" (1946/1998), en virtud de la disolución de la discontinuidad, la delimitación y el estaticismo de la noción tradicional de espacio, sumado a la incorporación de la variable del movimiento (Montaner, 1997), siendo uno de los más significativos aportes de esa revolución moderna que iniciaría varios siglos atrás con los avances de la ciencia, particularmente de la física y la astronomía.

\section{Arquitectura "Incontenible"}

Podemos asegurar que son muchos los teóricos del arte y la arquitectura que se han ocupado del problema del espacio arquitectónico moderno lecorbusiano, aunque tratar de abordarlos a todos es una labor que supera las expectativas de la presente investigación, creemos necesario referir algunos de las cuales pueden contribuir de manera más explícita a las distinciones de, al menos, dos de las maneras de reconocer la polaridad de dicho espacio en la arquitectura lecorbusiana.

Comencemos por señalar que es posible aceptar, sin caer en contradicciones que, en una mirada amplia la modernidad arquitectónica giró alrededor de dos nociones de espacio, como bien dice Giulio Carlo Argán:

Nos encontramos aquí frente a dos posiciones que tienden a dirigirse mutuamente. Una concibe el valor de la forma como algo que escapa a la percepción inmediata, de tal manera que postula una estructura inmaterial y liviana, lo menos evidente y plástica que sea posible, en tanto pretende que la forma se adhiera al concepto, que no sea más que la formulación de un concepto espacial. La otra, en cambio, tiende a la fenomenización, a poner en evidencia que cualquier manifestación de un concepto sólo puede verterse a través de valores de percepción, y que por lo tanto la forma arquitectónica debe conseguir una fenomenización concreta y no una abstracta delineación espacial (1982:167).

En relación al argumento de Argán podemos decir que en los primeros años del siglo XX las reflexiones en torno al problema del espacio se centraron en lo que podríamos llamar, por un lado, la configuración físico-espacial de la arquitectura en correspondencia con la idea de que ésta es el arte que moldea el espacio de manera uniforme definiendo los límites entre la interioridad y la exterioridad (Frampton, 1987) y por otro lado, hubo quienes fijaron su interés en lo que se ha conocido como la experiencia del espacio, es decir, la posibilidad de participar de la vivencia espacial en una dimensión ulterior superando la extensión física para convertirse en una forma de conocimiento cualificado (Kruft, 


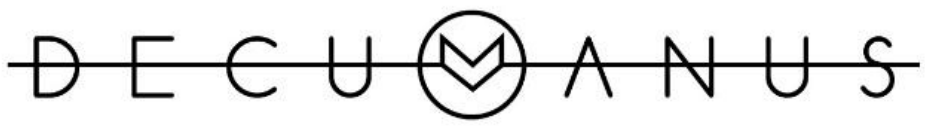

REVISTA INTERDISCIPLINARIA SOBRE ESTUDIOS URBANOS

1994). Sin detenernos por el momento en cuál de las dos nociones el Movimiento Moderno haya pretendido validar con el tiempo, es claro que desde las diferentes ópticas el espacio no fue considerado como un elemento más de la arquitectura, sino que se aceptó como su elemento definitorio por naturaleza. Sin embargo, vamos a explicitar esta aparente dicotomía.

Recordemos que en sus primeros años como pintor Le Corbusier militó al lado de Amédée Ozenfant y en compañía suya rápidamente propuso una tendencia sustitutiva del Cubismo pictórico denominada Purismo, pues a su entender el Cubismo había devenido en múltiples confusiones entre las cuales señalaron dos como las más críticas; la primera fue "el rechazo de la perspectiva lineal a favor del plano bidimensional y, finalmente, la descripción simultánea de diversos puntos de visión" (Van de Ven, 1981:238) que el Cubismo denominó la cuarta dimensión (Van de Ven, 1981). Detengámonos en ello.

El Cubismo dio un valor superior al lienzo, adquiriendo un nuevo estatus al superar el hecho de ser simplemente el fondo para convertirse en un plano constitutivo de la misma; en este sentido, la noción de espacio cuatridimensional implicaba contar con un observador posicionado frente al cuadro quien, adoptando múltiples puntos de vista frente a la obra, se supone conseguía una visión completa de la escena representada superando las posibilidades de comprensión que la perspectiva matemática podía proporcionarle (Fleming, 1989). Este argumento provocaría en el rechazo de Le Corbusier, pues, a su entender, de manera deliberada se había dejado de lado la perspectiva lineal sumado a que, cualquier intento de incluir una nueva dimensión, podría ser problemático al tratar de aproximar la noción de espacio al hombre real, puesto que el ser humano puede percibir y reconocer fundamentalmente tres dimensiones a través de sus sentidos.

Es posible pensar, en consecuencia, que Le Corbusier estaba intentando revalidar la noción tradicional de espacio que encontró en el Renacimiento su máxima expresión, pues en aquel espacio tradicional hay una diferenciación volumétrica clara y contundente que, sumada a la estaticidad, delimitación y especificidad de los planos de fachada y cubierta del edificio, permite la comprensión de un espacio contenido en el cual el hombre se sitúa en el centro representado por la perspectiva lineal matematizada por Brunelleschi, siendo, entonces, el espacio donde la posibilidad de aprehensión se dio a través de la geometrización y matematización de una tridimensionalidad homogénea (Huse, 1986).

No obstante, es suficiente con ir un poco más allá para comprender que los primeros años de la experiencia pictórica de Le Corbusier, la cual defendió a través de Apès le Cubisme - Después del Cubismo -, no estaba apelando por la homogeneidad espacial con el hombre en el centro del mismo, 


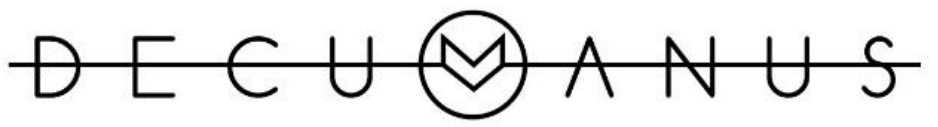

REVISTA INTERDISCIPLINARIA SOBRE ESTUDIOS URBANOS

sino que, valiéndose de la reflexión que había puesto de manifiesto la revolución copernicana, optó por introducir la noción de espacio dinámico el cual logra ser independiente y relativo al movimiento sin tener que caer, al menos no aún, en la cuatridimensionalidad (Montaner, 1997). Basta sólo con ver algunas de las primeras obras de Le Corbusier (Imagen 48) o del mismo Ozenfant para entender que en la génesis del Purismo y en su ulterior reflexión hacia la arquitectura purista, subyace el interés por movilizar el espacio; sin embargo, no está de más decir que habría de esperarse hasta el momento en que Albert Einstein formulara su Teoría de la Relatividad para comprender la situación en toda su dimensión.

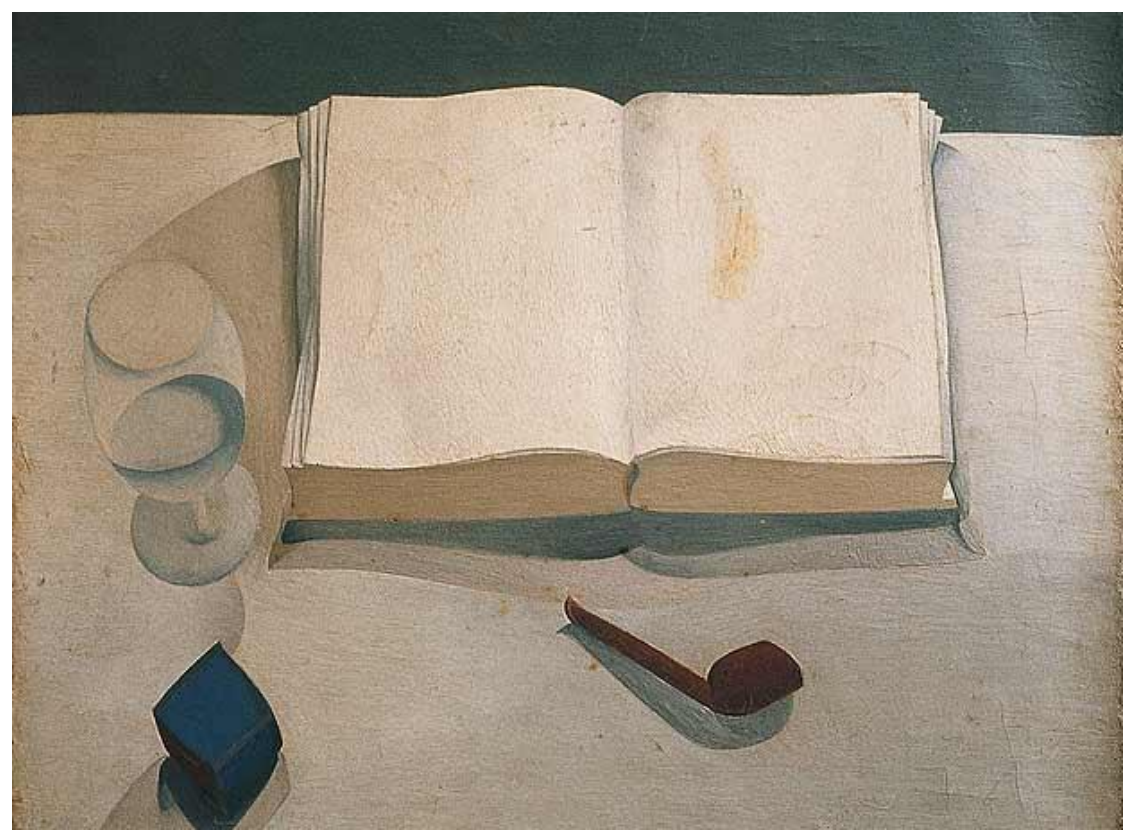

Imagen 1. Naturaleza muerta con vaso, libro, pipa y dado (www.elpais.com)

Le Corbusier se inició en la pintura dejando entrever un interés por definir los contornos bidimensionales de los objetos tridimensionales, dicha preocupación le permitió dirigir su camino hacia lo que fue la apariencia purificada del objeto que más tarde tomaría sentido al hablar de la desaparición de lo meramente ornamental en un arte que pretendía liberarse del lastre histórico de una tradición. Las formas puras bajo la luz, de las que años más tarde hablaría Le Corbusier el pintor como el arquitecto, no eran producto de un delirio sin sentido frente al universo maquínico, como han señalado sus detractores, sino que eran un retorno a lo esencial, a la ontología de las volumetrías claras y simples que la geometría describía, las cuales encontrarían en el escenario del purismo 


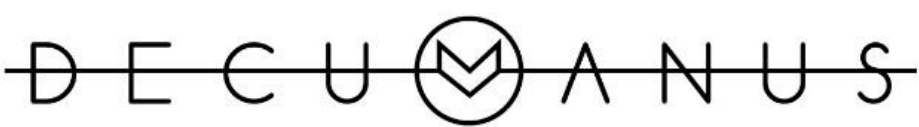

REVISTA INTERDISCIPLINARIA SOBRE ESTUDIOS URBANOS

arquitectónico y su noción de espacio dinámico de la década del veinte, su máximo desarrollo (Subirats, 1999).

Ahora bien, si trasladáramos esta misma reflexión a la primera década del siglo XX donde Le Corbusier se inicia también como arquitecto, nos encontraríamos frente al primer escenario que hemos descrito donde las aproximaciones al problema del espacio se hacían desde el plano fundamentalmente físico. En este sentido, podemos apelar a los argumentos de los teóricos que explícitamente se han referido al tema, por ejemplo Bruno Zevi (1981), quien consideró que la arquitectura, a diferencia de las otras artes pero particularmente en oposición a la escultura, tenía como finalidad dar cobijo al hombre; de hecho, la función práctica de proporcionar abrigo estaría directamente relacionada con la conformación de un espacio interior claramente contenido y diferenciado en contraposición a un espacio exterior abierto, indiferenciado y extenso casi ad infinitum.

En consecuencia, el espacio físico requería de la vinculación de una materialidad con un despliegue funcional que sólo se definía y determinaba por el lenguaje tridimensional que movilizaba, de manera que el espacio se convertía en la manifestación extensa de la geometría. Las primeras arquitecturas realizadas por Le Corbusier, previas a la publicación de Après le Cubisme y Vers une Architecture, como la Casa Fallet de 1906 - 1907 (Imagen 2), la Casa Janneret-Perret de 1912 (Imagen 3) o la Villa Schowb de 1916 (Imagen 4), todas ellas realizadas en su natal Chaux-de-Fonds en Suiza, muestran composiciones claramente simétricas, techumbres fuertemente inclinadas, planos de fachada poco horadados y casualmente ornamentados, todas ellas edificaciones construidas con materiales propios de la región que, entre otros, parecerían apelar más a los estereotipos de la arquitectura tradicional alpina que, en rigor, eran arquitecturas que respondían a la concepción tradicional de un espacio físico estático y a la noción diferenciada de un interior cerrado y privado versus un exterior abierto y público. 


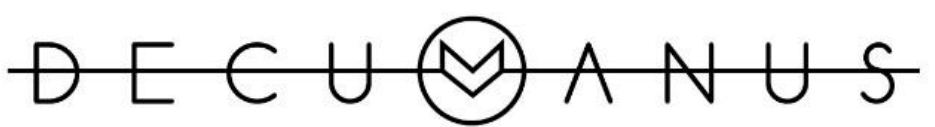

REVISTA INTERDISCIPLINARIA SOBRE ESTUDIOS URBANOS
Núm. 1 Vol. 1. Octubre 2015 - Octubre 2016 Instituto de Arquitectura, Diseño y Arte

Universidad Autónoma de Ciudad Juárez ISSN: $2448-900 X$

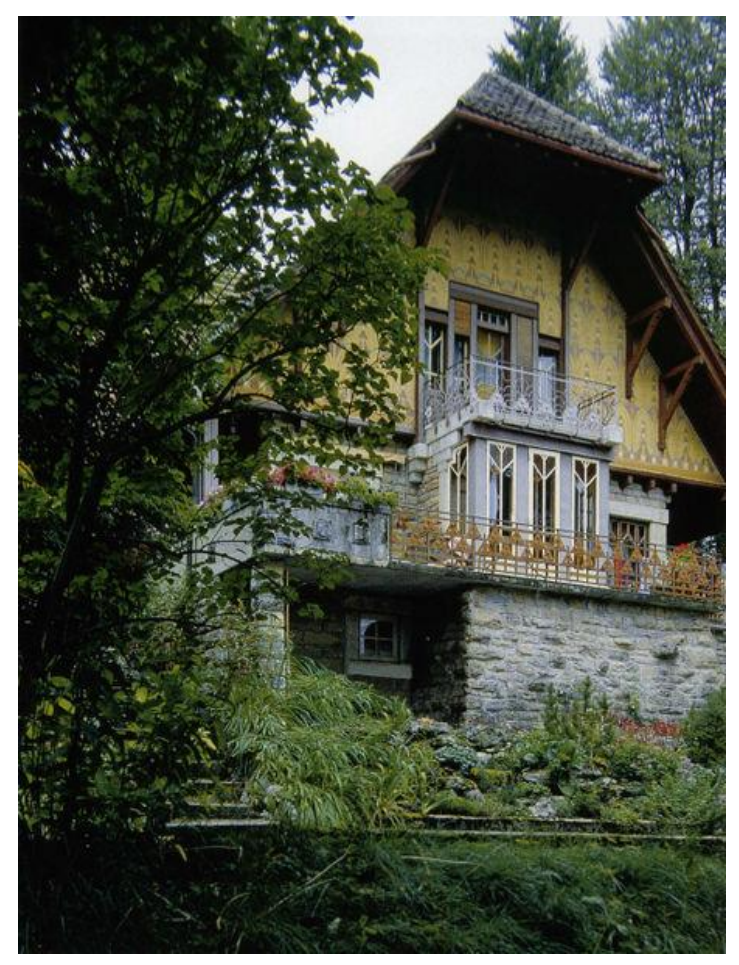

Imagen 2. Casa Fallet (www.wikiarquitectura.com)

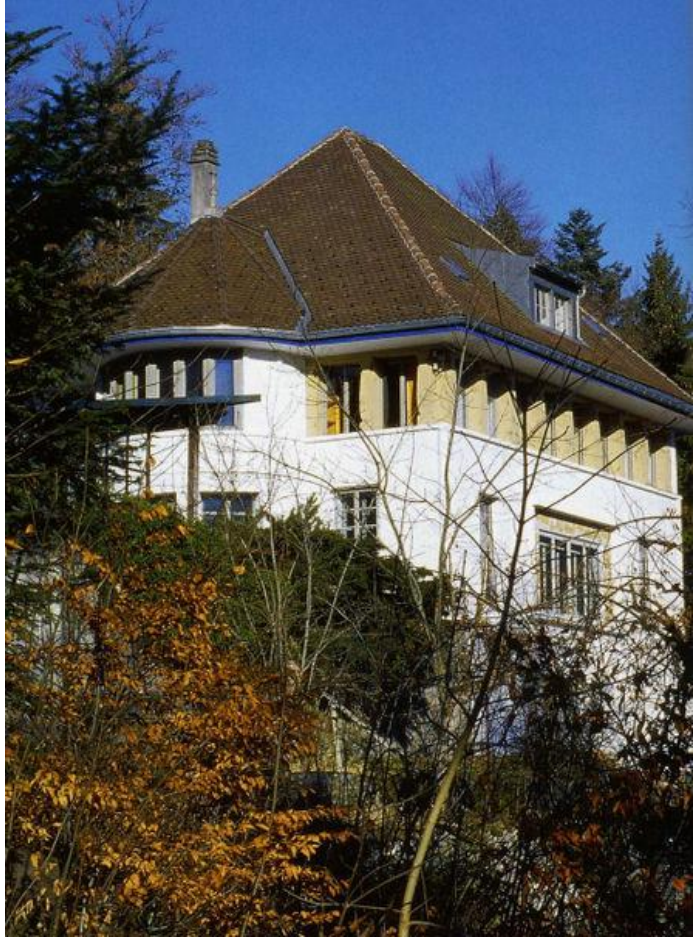

Imagen 3. Casa Janneret-Perret (www.wikiarquitectura.com)

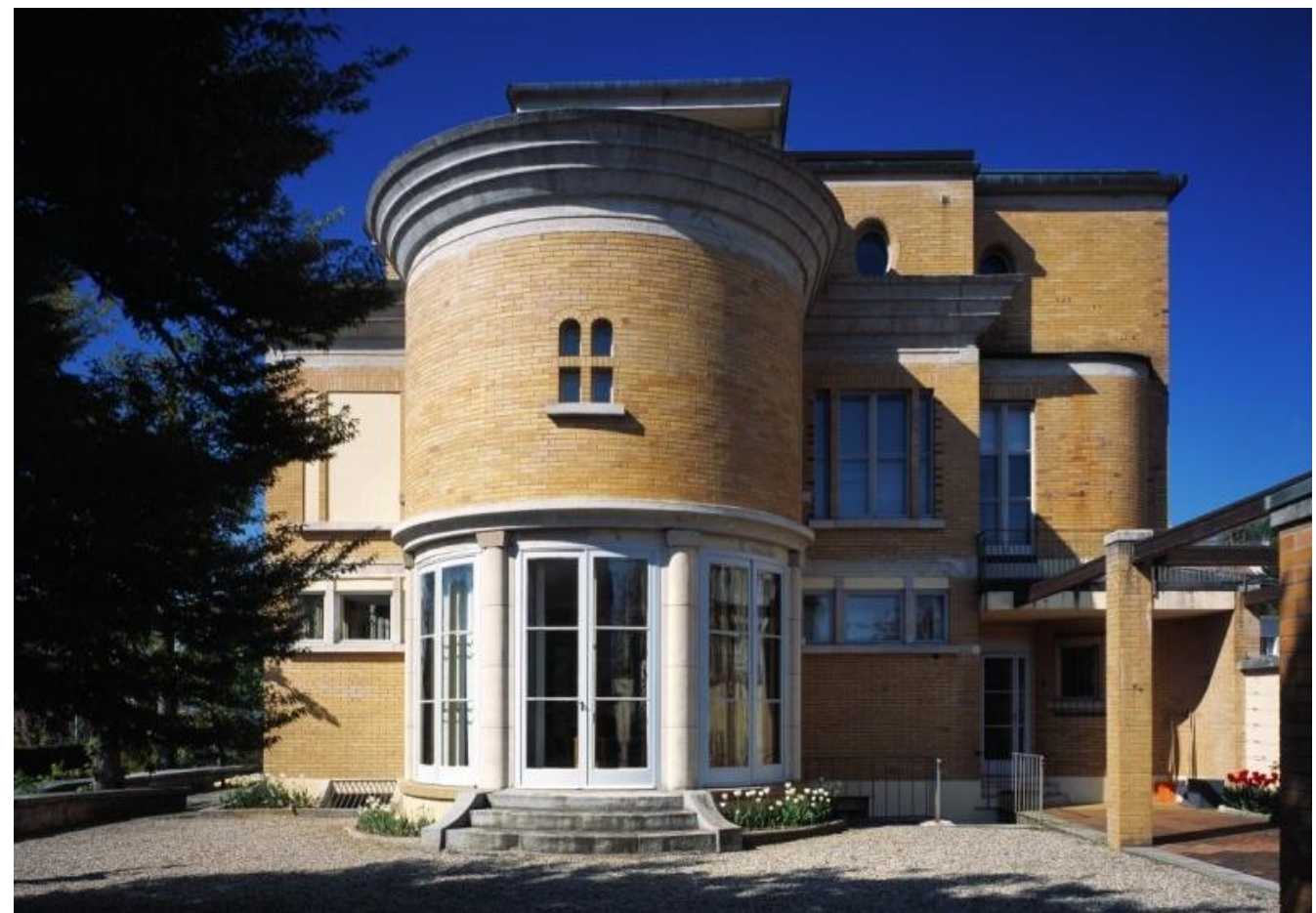

Imagen 4. Villa Schowb (www.wikiarquitectura.com) 


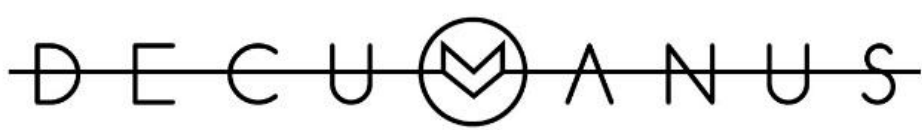

REVISTA INTERDISCIPLINARIA SOBRE ESTUDIOS URBANOS
Núm. 1 Vol. 1. Octubre 2015 - Octubre 2016

Instituto de Arquitectura, Diseño y Arte

Universidad Autónoma de Ciudad Juárez

ISSN: $2448-900 X$

Aunque en un primer escenario podríamos asegurar que las explicaciones de Zevi (1981), muy próximas también a las de Sigfried Giedion (1986), se pudieron quedar un tanto cortas en relación al espacio como elemento definitorio de la arquitectura, pues en últimas permanecen ancladas al plano de lo físico y material, también es cierto que pronto comenzarían a dejar entrever que el espacio era el continente de los ideales de una época donde el hombre logró su existencia, lo cual en buena medida, era una posición bastante sugerente frente a la idea que vendría a participar de la noción relacional entre lo físico de un espacio cuantitativo y la posibilidad de la experiencia de un espacio cualitativo.

Bastaría sólo esperar unos años para que Charles-Édouard Jeanneret se adentrara en el mundo de la pintura y la arquitectura purista dejando atrás buena parte de la tradición que le había acompañado, dejara definitivamente su natal Chaux-de-Fonds para viajar a París, donde adoptaría el seudónimo de "Le Corbusier" para fundar la revista L'Esprit Nouveau cambiando casi por completo su noción de arquitectura y, por ende, su idea de espacio. Para aquel entonces era necesario comenzar por redefinir claramente los elementos constitutivos de la tridimensionalidad arquitectónica, siendo su respuesta: el volumen, la superficie, el plan y los trazados reguladores; los tres primeros fueron desarrollados en el segundo capítulo de "Hacia una Arquitectura" (Le Corbusier, 1930[1998]) denominado Tres advertencias a los señores arquitectos y al cuarto dedicó exclusivamente un capítulo que lleva su mismo nombre. Decía Le Corbusier:

Ha llegado el momento de presentar el problema de la casa, de la calle y de la ciudad, y de confrontar al arquitecto con el ingeniero. Para el arquitecto, hemos escrito las TRES ADVERTENCIAS: EL VOLUMEN, que es el elemento por el cual nuestros sentidos perciben, miden y son plenamente afectados. LA SUPERFICIE, que es la envoltura del volumen y que puede anular o ampliar la sensación. El PLAN, que es el generador del volumen y de la superficie y mediante el cual todo está irrevocablemente determinado. Luego, también para el arquitecto, están los TRAZADOS REGULADORES que muestran de este modo uno de los medios por los cuales la arquitectura logra esa matemática sensible que nos da la impresión bien-hechora del orden. Aquí hemos querido exponer hechos que valen más que las disertaciones acerca del alma de las piedras. Nos hemos quedado en la física de la obra, en el conocimiento (1930[1998]).

Para Le Corbusier estos cuatro elementos participarían de la conformación arquitectónica del espacio; sin embargo, no serían exclusivamente los únicos. La gran diferencia con su primera postura frente al tema, la misma que había devenido en purismo como hemos mencionado ya, es que el quinto 


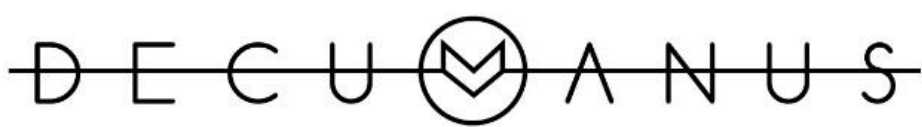

REVISTA INTERDISCIPLINARIA SOBRE ESTUDIOS URBANOS
Núm. 1 Vol. 1. Octubre 2015 - Octubre 2016

Instituto de Arquitectura, Diseño y Arte

Universidad Autónoma de Ciudad Juárez

ISSN: $2448-900 X$

elemento que, aunque distante de la postura cubista, configuraría la espacialidad arquitectónica: el hombre. En consecuencia, el sujeto no se situaría como el simple observador que, estático, se mantiene en el centro de lo definido por la materialidad, sino que descargaría precisamente en él la posibilidad misma de existencia del espacio arquitectónico a partir de la experiencia, es decir, pondría en manos del hombre la posibilidad de conocer y construir las diferentes visiones del espacio a partir de su posibilidad real de desplazarse y moverse en él, tanto así, que los otros cuatro elementos que conformaban la tridimensionalidad del edificio estarían pensados para diluirse con el ánimo de permitir que el movimiento trascendiera los límites de lo corpóreo para que la experiencia pudiera extenderse fuera de ellos y lo que podría ser claramente comprendido como la incorporación de la relatividad, ahora al servicio de la experiencia espacial del edificio.

Sobra decir, que lo que Le Corbusier había rechazado enérgicamente del Cubismo cuando había referido la inoperancia de la cuatridimensionalidad, terminaría, claramente, participando de su nueva noción de espacio, pues daría un valor significativo a la percepción del sujeto que habita el edificio por ser él quien hace posible la configuración espacial plena, sin dejar de lado sus dudas frente a la manera que el Cubismo lo sugirió y prefiriendo apelar a un "algo bautizado cuarta dimensión, si, al fin y al cabo, es subjetivo y de naturaleza irrefutable pero indefinible y no euclidiano" (Le Corbusier, 1946/1998:50) y de manera un tanto más extensa quiso dar sentido a una nueva forma de definición espacial, el indecible.

La cuarta dimensión, parece ser el momento de evasión ilimitada, provocada por la consonancia excepcionalmente justa de los medios plásticos puestos en acción y por ellos maniobra. No es un efecto del tema elegido, sino una victoria de la proporción en todas las cosas, tanto en los aspectos físicos de la obra como en la eficiencia de las intenciones, reguladas o no, aprehendidas o inaprensibles $y$, no obstante, existentes y deudoras de la intuición, milagro catalizador de saberes adquiridos, asimilados, aunque tal vez olvidados. Pues en una obra, terminada y lograda, hay masas de intención enterradas, un verdadero mundo, que se revela a quien tiene derecho a entender, vale decir: a quien se lo merece. Entonces surge una profundidad sin límites, que borra los muros, ahuyenta las presencias contingentes: realiza el milagro del espacio indecible (Le Corbusier, 1946/1998:48).

Este nuevo modo de, digamos así, de liberar la dimensión experiencial del espacio llevaría, sin lugar a dudas, a jerarquizar la arquitectura con respecto a las demás artes visuales, pues, en buena 


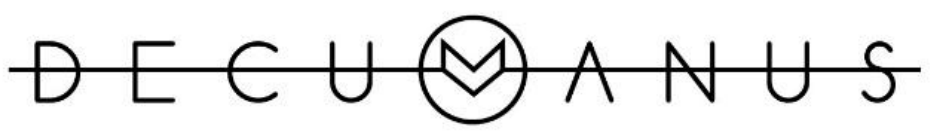

REVISTA INTERDISCIPLINARIA SOBRE ESTUDIOS URBANOS

medida, el que ésta apelara por ser la perfecta expresión de un proyecto de mundo se correspondería con el grado de inmaterialidad del medio expresivo utilizado y, por naturaleza, el espacio sería el medio menos material de todos alcanzando así, una preponderancia casi absoluta (Van de Ven, 1981).

En este sentido, valga recurrir nuevamente a las llamadas Villas Puristas donde Le Corbusier, de manera excepcional, desplegaría lo que se ha conocido como los cinco puntos de la nueva arquitectura que básicamente harían referencia a la relación de los elementos materiales del edificio con la experiencia espacial del mismo y que, en el fondo, tendería a la revelación de la forma espacial más allá de la forma material del objeto arquitectónico (Argan, 1982).

Podríamos tomar un edificio como la Villa Savoye en Poissy (Francia) de 1929 para ejemplificar más claramente los argumentos lecorbusianos en mención. Primero, está el edificio sobre pilotes que sustituye el papel estático de los muros portantes, éstas esbeltas columnas localizadas en el mismo hilo del plano general de fachada a manera de palafitos elevan el edificio permitiendo que el continum horizontal de la planta baja fluya libremente sin encontrar, digamos así, fragmentaciones de ningún tipo, pues aunque el edificio también se apoya sobre un volumen de menor proporción, casi la mitad de este cuerpo esta acristalado y poco menos de la otra mitad está configurada por un muro curvo continuo intencionalmente pintado de color verde que se mimetiza con el color de la grama, lo cual hace posible contar con un jardín ininterrumpido a nivel de piso, una especie de falsa elevación de todo el edificio para afectar visualmente al observador y para permitir todo tipo de actividades recreativas o de ocio (Imágenes 5 y 6) que parecen eliminar la mayor masa posible apoyada directamente sobre la tierra, con lo cual el edificio se despide del requerimiento tradicional de pesantez para acercarse a la liviandad propia de las nuevas arquitecturas en concreto reforzado que, serenamente, logran ir desmaterializando los requerimientos de tipo físico-corpóreo del edificio para corresponderse mejor con las intenciones que subyacían en la profundidad óntica, que hemos mencionado unas páginas atrás, que la edificación pretendía materializar (Torres Cueco, 2004).

Ahora, partiendo de esta planta baja y desde el interior se sitúan los ejes articuladores que en sentido vertical definirán la disposición de los habitáculos a medida que se asciende, son estos una escalera y una rampa central que rematan en la terraza-jardín. A partir del segundo nivel se evidencian la planta libre y la fachada flotante, donde la primera se corresponde con la ausencia de muros internos divisorios fijos en cuyo caso serán sustituidos por tabiques más delgados y livianos, no ligados a la estructura, que pueden ser removidos o reubicados con el ánimo de lograr ampliar o reducir el tamaño de un espacio y, la segunda, hace referencia a que los muros de fachada son totalmente independientes de la estructura portante del edificio logrando, así, liberar, tanto materialmente como 


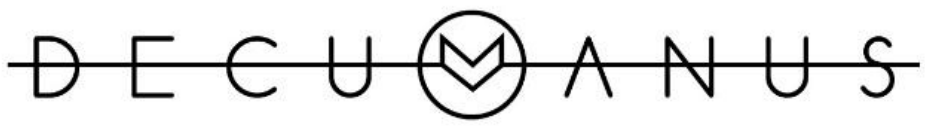

espacial y compositivamente, el interior de la planta de la superficie contenedora (Imágenes 7 y 8 ), tal y como señala el mismo Le Corbusier, citado por Sbriglio:

El plano moderno de la construcción en acero u hormigón, es decir postes aislados y tabiques a discreción, es ahora un plano libre. Ya no se trata de muros que se cruzan en ángulo recto, formando piezas cuadradas que una puerta cierra y una ventana abre. Ahora, el local es como un continente que puede ser tabicado y eso ya no da lugar a la pieza que se llama sala de estar, comedor, etc., sino que da complejos de forma. En esas condiciones, por economía, gracias a una ubicación precisa, a una ubicación hábil de los tabiques, de las circulaciones y de las puertas, gracias a la altura de las piezas y al color, se puede aportar una variedad extraordinaria y superar obstáculos impuestos por la biología de nuestra concepción (2005:129).
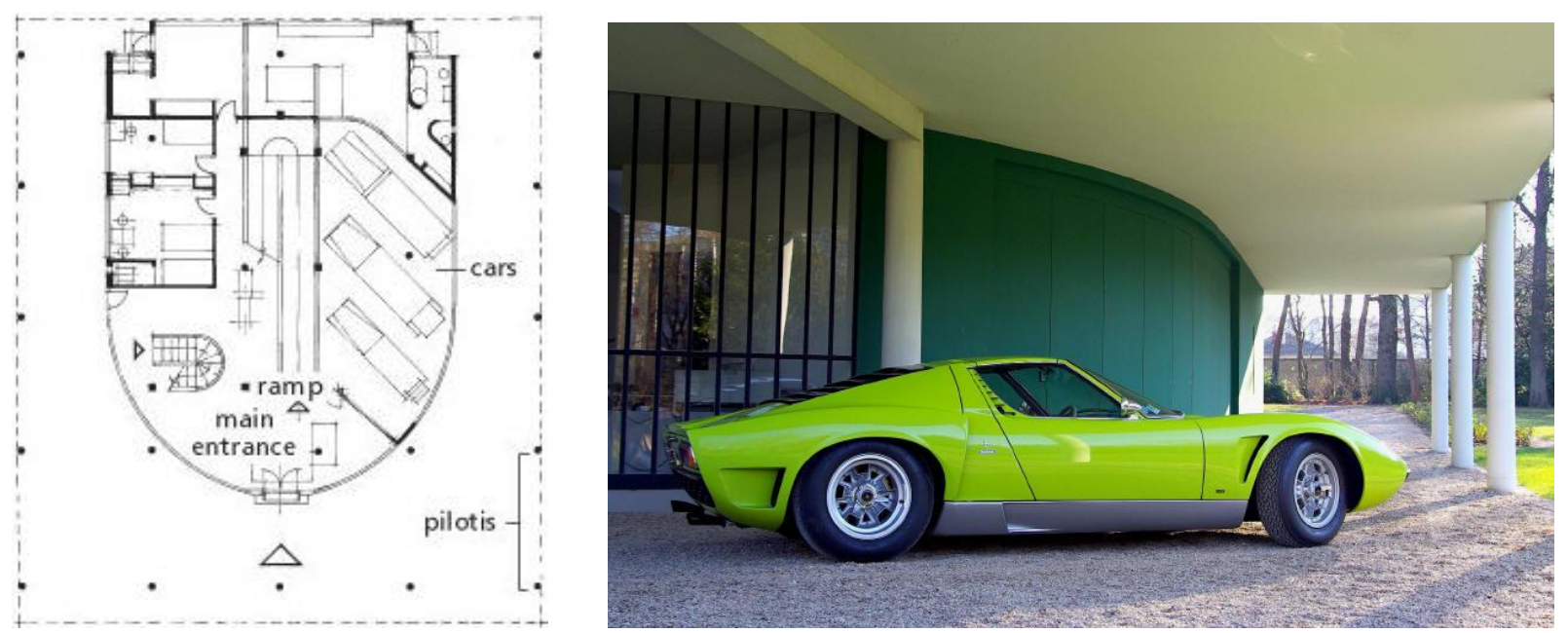

Imagen 5. Planta baja (www.contentanswers.com) Imagen 6. Planta sobre pilotes bajo la cual circula libremente un vehículo (www.autodrome.fr) 


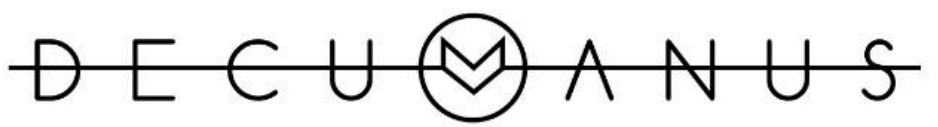

REVISTA INTERDISCIPLINARIA SOBRE ESTUDIOS URBANOS

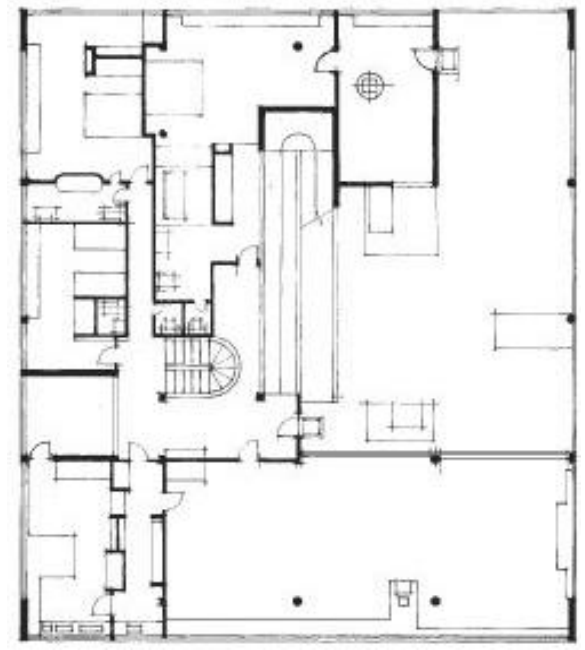

Imagen 7. Segundo piso (www.contentanswers.com)

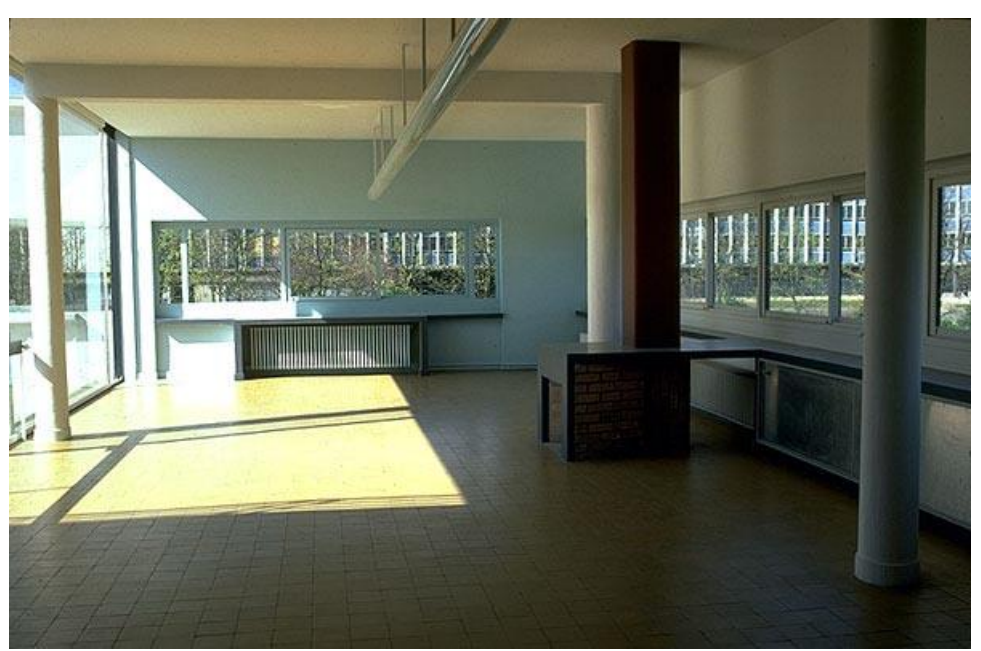

Imagen 8. Vista sobre la planta libre del salón-comedor y fachada flotante

(www.brynmawr.edu)

A partir de entonces, las fachadas no sólo se desprenden de la planta y de la estructura del edificio, sino que, además, se incorpora la ventana corrida o vano horizontal (Imágenes 9 y 10) que permitirá que el habitante logre captar la esencia de un espacio incontenible que permea los límites materiales entre el interior y el exterior; de esta manera, con una ventana acristalada que no presenta interrupciones, es decir, un vano que inicia casi en un vértice donde se encuentran los muros de fachada y remata en el extremo opuesto en las mismas condiciones y de igual forma en todas las caras del volumen, sin ser simétrica por supuesto, poco tiene que ver con las divisiones internas que configuran los habitáculos o la distribución de la planta misma y más bien se relaciona con la idea de que el espacio dinámico de la modernidad, no posee una estructura fija y se enfrenta constantemente a las transformaciones producto de las visiones del espectador y de la materia que lo contiene.

Finalmente, el edificio termina en una tercera planta convertida en terraza-jardín (Imágenes 11 y 12) que también hace las veces de cubierta de los pisos inferiores, pues Le Corbusier consideraba que un verdadero jardín no podría hallarse a nivel de piso sino que éste debía elevarse de manera que desde arriba pudiera contemplarse, en trescientos sesenta grados, la vastedad del paisaje; de este modo, la fluidez espacial con que comienza el edificio desde su primer nivel, el continuum que permanece en la planta siguiente y el remate en una cubierta plana que, a manera de terraza, permite ser recorrida y todos ellos articulados por la rampa y la escalera helicoidal, que terminan por configurar lo que Le Corbusier creyó era el espacio de la arquitectura moderna, una obra inacabada que se recrea desde lo más profundo de su configuración interna en virtud de las relaciones que podríamos 


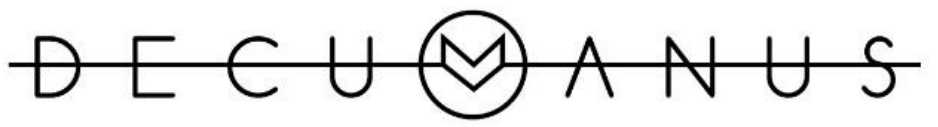

REVISTA INTERDISCIPLINARIA SOBRE ESTUDIOS URBANOS

denominar fenomenológicas, tal y como lo hace Argán, partiendo de la descomposición geométrica de los elementos materiales y reconfigurando la experiencia espacial de la unidad arquitectónica (Argan, 1982).

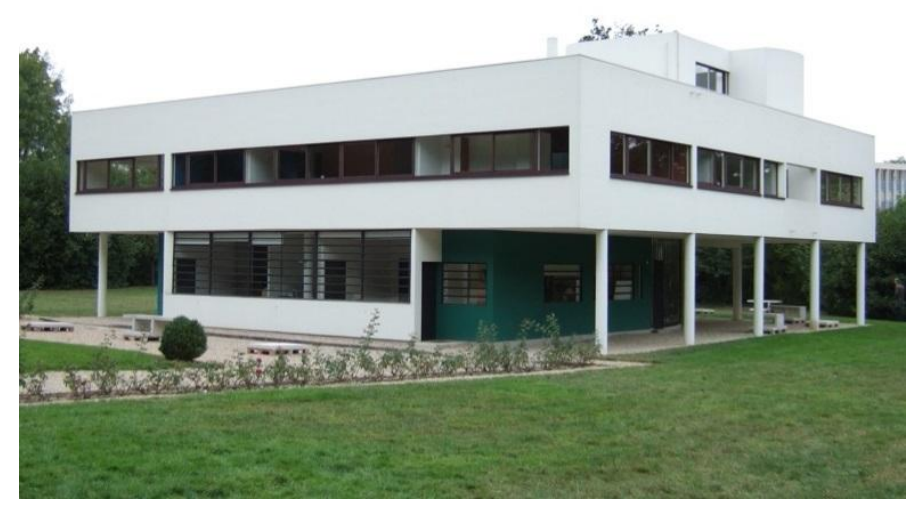

Imagen 9. Vista de las Fachadas Norte y Occidental (www.taringa.net)

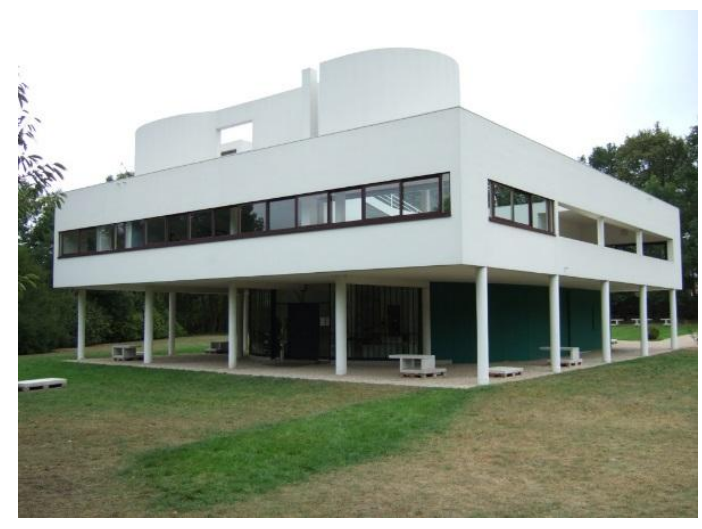

Imagen 10. Fachada Sur y Oriental (www.taringa.net)

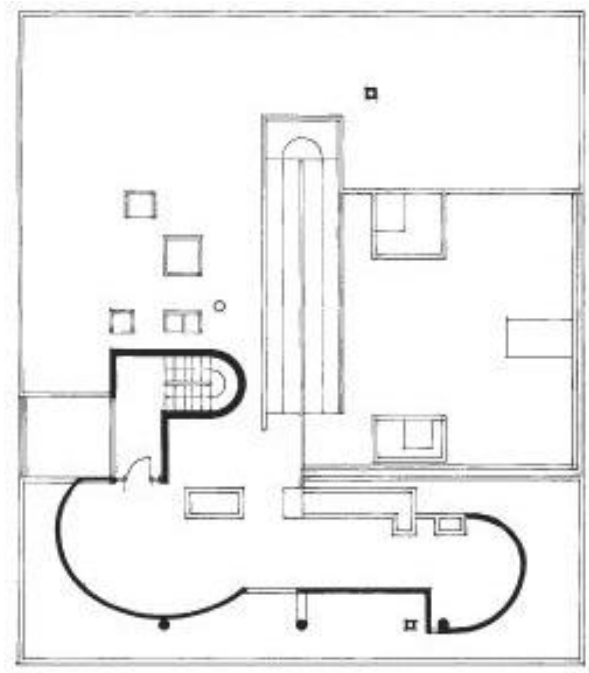

Imagen 11. Terraza jardín (www.contentanswers.com)

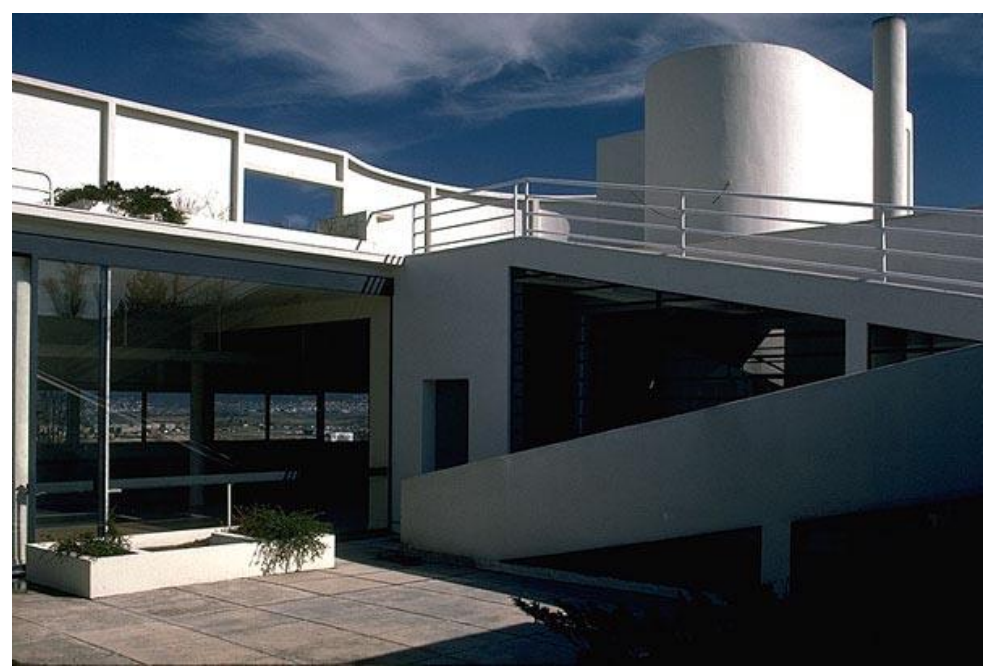

12. Vista desde la terraza jardín de segundo piso hacía el tercero (www.brynmawr.edu)

En rigor, podríamos sugerir la existencia de al menos tres elementos que conforman la arquitectura de la modernidad lecorbusiana. En primer lugar, estarían los elementos susceptibles a ser percibidos por los sentidos y que se caracterizan por la fisicidad del hecho arquitectónico; en segundo lugar, la correspondencia de dicha fisicidad, es decir, la copertenencia del sustrato material con el proyecto de 


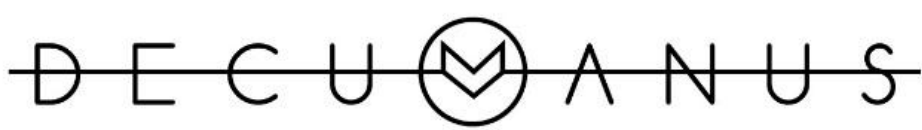

REVISTA INTERDISCIPLINARIA SOBRE ESTUDIOS URBANOS
Núm. 1 Vol. 1. Octubre 2015 - Octubre 2016

Instituto de Arquitectura, Diseño y Arte

Universidad Autónoma de Ciudad Juárez

ISSN: 2448-900X

mundo que expresa y, por último, estaría la capacidad inherente que tiene el edificio de dejarse impactar por quien lo habita en razón de la posibilidad del sujeto de evidenciar en él su propia vivencia espacial, de manera que, como señala Bollnow:

El espacio se convierte entonces en forma general de la actitud vital humana. Como ser creador y desplegador del espacio, el hombre necesariamente no es sólo el origen sino también el centro permanente del espacio, pero no de la manera en que el caracol lleva su casa sino en el sentido que el hombre se mueve en su espacio dentro de una correspondencia entre el espacio vivencial del hombre y la espacialidad de la vida humana (1969:33).

Con ello queda establecido que la arquitectura poseía una realidad espacial que superaba ampliamente cualquier consideración de orden meramente físico y que difícilmente podría existir al margen de la relación existencial que establecía con el sujeto que la habitaba, con lo cual reafirma su noción de correspondencia entre la profundidad óntica de la arquitectura y su subsecuente materialización en el hecho arquitectónico vivificado por el sujeto que realiza en él su experiencia estética, por encima de cualquier consideración puntual de orden cultural para, más bien, dar sentido al ser en el mundo. En la medida que Le Corbusier fue aceptando que el hombre establecía relaciones con el contexto, entendido como mundo en que se hallaba, situación que, de hecho, vincularía la arquitectura al ser mismo, fue conduciendo su reflexión hacia la comprensión profunda del problema legítimo del que la arquitectura realmente se ocupaba y, en su caso, a partir de ese momento no abandonaría jamás: el hombre.

Es claro, entonces, que la modernidad que se instala a comienzos del siglo XX, en todas sus dimensiones, aparece como un proyecto que comenzó por deshacer la noción de mundo que alguna vez sustentó y validó los propósitos culturales de occidente (Subirats, 1999) (Jeckns, 1980), es decir, dejó de lado la concepción visual, cartográfica y fraccionaria, si se quiere, del espacio y de las características particulares que lo definen en razón de lo que podríamos llamar cultura y tradición. No obstante, estaríamos hablando de lo que Otl Aicher (2001) prefiere definir como lo digital en contraste con lo analógico; para Aicher, la modernidad es un proyecto determinado por un pensamiento claramente digital, es decir, una apuesta de mundo determinada por una noción racional y cuantitativa de mundo distante de cualquier correspondencia con la percepción sensorial del mundo, es decir, desvinculada de las relaciones y valoraciones cualitativas del mundo, lo que él mismo Aicher denominó pensamiento analógico. Podríamos decir que para Aicher, por ejemplo, el espacio de la arquitectura 


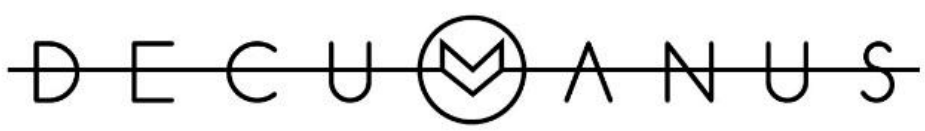

REVISTA INTERDISCIPLINARIA SOBRE ESTUDIOS URBANOS

moderna es un espacio claramente digital, pues se corresponde con un valor absoluto, preciso, matemático y radicalmente cartesiano que nada tiene que ver con la experiencia analógica de vivenciar el espacio cualitativamente.

Sin embargo, a nuestro entender nuevamente la posición de Aicher (2001) podría ser una visión un tanto radical frente a los argumentos elevados por los pioneros del Movimiento Moderno en su afán por construir una nueva noción de espacio, que si bien es cierto en sus comienzos, tal y como hemos visto en el caso de las primeras arquitecturas, pudo desligarse de tajo de los problemas de la percepción y construcción relacional que el hombre hace de ese mismo espacio, ya en la década del treinta es evidente que lo que buscaron fue construir un espacio más dinámico, incontenible y versátil, probablemente menos loable en virtud de la tradición, pero ciertamente más próximo a lo que el mismo Aicher define como analógico al referirse a la experiencia cualitativa de las creaciones humanas, tal y como hemos descrito en el ejemplo de Le Corbusier y la Villa Savoye.

Desde nuestra óptica Aicher ha confundido, en buena medida, la desnudez y el rechazo al ornamento que se hizo evidente en los edificios de la primera posguerra sumado a la posición a histórica de la misma modernidad, con una erradicación de cualquier tipo de experiencia, digamos así, sensorial y humana de la arquitectura situación, a nuestro juicio, poco probable en una arquitectura que se ocupaba, fundamentalmente, en dar al hombre un mejor mundo habitable, al menos en su apuesta discursiva donde se luchó por la necesidad de universalizar el acceso al espacio doméstico o la participación abierta y colectiva de lo público.

De hecho, podríamos considerar que fue probablemente la imagen aséptica de los edificios blancos y sus formas puras bajo la luz lo que llevó a Aicher a sugerir la idea de que la modernidad lecorbusiana sólo se ocupaba del espacio neutro cuantitativo diferenciado sólo por las variables $x-y$, pero también valdría decir que un personaje de la agudeza de Aicher no pudo simplemente ignorar los cinco puntos de la nueva arquitectura y las amplias explicaciones que de ellos hace el mismo Le Corbusier y que seguramente no pasaron inadvertidas manifestaciones más sutiles pero igualmente contundentes como las apuestas por el uso del color con el ánimo de cualificar los elementos materiales que participan de la composición del espacio arquitectónico, no sólo en algunos paños de fachada con propósitos tan claros como las descritos en la Villa Savoye sino en el interior de otras villas puristas como la casa La Roche e incluso en los proyectos que vendrían posteriormente como los de casas en serie y la misma Unité d’Habitation; es más, ¿será posible que Aicher no haya sabido de la capilla de Ronchamp du Haut, un edificio con el que se ha considerado que Le Corbusier supera el dilema de la descomposición geométrica sugerida por cubistas y puristas y logra "con su sola 


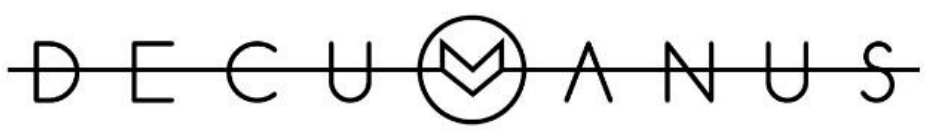

REVISTA INTERDISCIPLINARIA SOBRE ESTUDIOS URBANOS

presencia en la realidad existencial" materializar una nueva noción de espacio identificada con los contenidos ideológicos de una época siendo consciente, además, que ello implicaba cierta definición de mundo, "porque toda forma que logra un valor de plena espacialidad se transforma por este mismo hecho en una imago mundi, en una condición del mundo?” (Argan, 1982:174), ¿será que Aicher no conoció los textos escritos por Le Corbusier como el mismo Hacia una Arquitectura o la Casa del Hombre o el corto artículo llamado El Espacio Indecible donde hace explicita referencia a su preocupación por el establecimiento del hombre en el mundo y su posibilidad de aproximarse a él a través de una experiencia cualificada como la vivencia del espacio?

A nuestro entender, es realmente poco probable que Aicher no haya visto los edificios lecorbusianos o no haya tenido conocimiento de la amplia literatura escrita por él; nos atrevemos a sugerir que, de manera un tanto generalizante, Aicher, como un gran número de detractores de dicha modernidad, decidió medir con el mismo rasero los aciertos y desaciertos de la modernidad arquitectónica indistintamente de las particularidades de sus corrientes y sus exponentes, pero sobretodo, nos parece evidente que Aicher no hizo distinción entre el Movimiento Moderno de la Arquitectura, desarrollado en Europa aproximadamente durante la primera mitad del siglo XX, y el International Style (Jeckns, 1980), que aparece en los Estados Unidos y prolifera indistintamente casi por el mundo entero a partir de la década del treinta y hasta buena parte de los setenta, situación que no contribuye mucho a las objeciones presentadas por él frente a la arquitectura lecorbusiana.

De otro lado, Aicher no diferencia tampoco, al menos no de manera clara, al Le Corbusier de lo que podríamos llamar tres tiempos, es decir, Aicher (1994) habla de tres modernidades y hace un amplio análisis de ellas mencionando incluso cuáles arquitectos y cuáles arquitecturas hacen parte de cada una instalando a Le Corbusier en su segunda modernidad, pero no considera de manera independiente al Le Corbusier de los primeros años del siglo XX a quien podríamos ejemplificar a través de sus primeros edificios en la Chaux-de-Fonds, al Le Corbusier de entre guerras o el de las villas puristas y al Le Corbusier de la postguerra o el de la Unité d'Habitation, Ronchamp y Chandigard, los cuales, digamos así, no caben en la segunda modernidad aicheriana, pues, en consecuencia con lo que Le Corbusier pensaba, cada uno dio respuestas a las necesidades de mundo de una sociedad particular y en un momento determinado. Cómo hemos mencionado con anterioridad no vamos a dedicar esta investigación a objetar a Aicher pero tampoco lo vamos a pasar de largo sin dar ciertas respuestas a sus aseveraciones, con lo cual vemos oportuno terminar el presente apartado abordando al tercer Le Corbusier, pues ya hemos hablado en extenso sobre los dos primeros. 


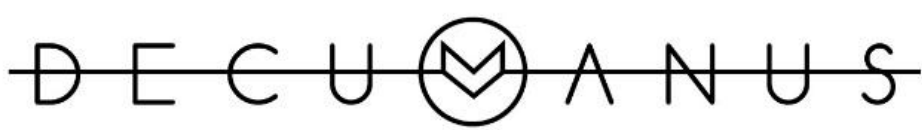

REVISTA INTERDISCIPLINARIA SOBRE ESTUDIOS URBANOS
Núm. 1 Vol. 1. Octubre 2015 - Octubre 2016

Instituto de Arquitectura, Diseño y Arte

Universidad Autónoma de Ciudad Juárez

ISSN: $2448-900 X$

Para entender los cambios en la noción de espacio que definió el Movimiento Moderno de la Arquitectura, es necesario comprender un suceso fundamental en la historia de la ciencia que se dio a comienzos del siglo XX: la Teoría de la Relatividad de Einstein (2000), la cual fue, fundamentalmente, una respuesta a los interrogantes acerca del espacio, el tiempo y la estructura de la totalidad del universo, inquietudes a las que la física clásica ya no supo dar explicación. En rigor, Einstein refutó la existencia de un espacio absoluto, tal y como lo propuso Newton, en cuya esencia estaba la idea de ser un sistema de referencia físico, continuo y homogéneo en el que la materia residía como si fuera un recipiente en estado de estaticidad total, es decir, desechó la idea de un contenedor inmóvil que no se afectaba por ninguno de los elementos físicos o hechos que se sucedían en él. Para Einstein el espacio era un continuo en cuya naturaleza no podía residir una estructura fija, pues se veía afectado por las transformaciones que producían los elementos materiales y los acontecimientos que permanentemente se sucedían en él. En consecuencia, esta nueva noción de espacio demandó una revisión del proceso de creación de los hechos artísticos y arquitectónicos y del rol que frente a ellos o en ellos desempeñaba el espectador.

Ahora bien, después de las dos guerras mundiales que devastaron al continente europeo y, de hecho, en buena medida afectaron al mundo entero, las artes y, entre ellas, la arquitectura acometió la tarea de, digamos así, flexibilizar sus estructuras gnoseológicas con el ánimo de lograr dar explicaciones más amplias a la complejidad del ser humano que le permitieran ajustarse, de manera absoluta y consciente, a su dependencia ontológica del mundo. El contexto cultural que quedó después de la guerra otorgó, de manera decisiva, al hombre un escenario de posibilidad de hacer real y de realizarse en el mundo, tanto así, que la arquitectura, por ejemplo, dejó de ocuparse de modelar el espacio físico, como pudo suceder con Le Corbusier en los primeros años del siglo XX superando, incluso, las reflexiones unidas al problema concreto de la geometría y las relaciones entre los objetos, para ocuparse, de manera decisiva, de la definición espacial determinada por el contexto existencial de sujeto que percibía y experimentaba el espacio de manera única. En este sentido, Le Corbusier escribiría, a finales de la década del cuarenta, un artículo llamado "El espacio indecible" el cual se sitúa en el preciso lugar de los primeros años de la segunda posguerra cuando era necesario que la arquitectura asumiera una posición de responsabilidad social con una nueva postura frente a la tarea de reconstruir Europa. Decía:

En este año de 1945, millones de damnificados sin abrigo, claman desesperadamente por una transformación inmediata de su situación. En las líneas que siguen se habla de alcanzar una perfección absoluta en la ocupación 


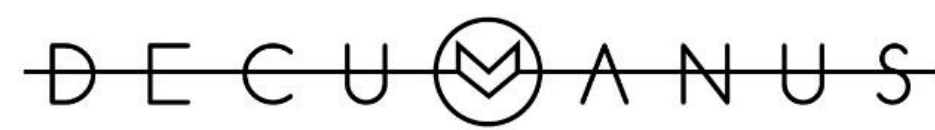

REVISTA INTERDISCIPLINARIA SOBRE ESTUDIOS URBANOS
Núm. 1 Vol. 1. Octubre 2015 - Octubre 2016

Instituto de Arquitectura, Diseño y Arte

Universidad Autónoma de Ciudad Juárez

ISSN: 2448-900X

del espacio, de las nuevas ciudades, uno se eleva a problemas de plástica desinteresada, búsquedas que frisan más en lo sagrado que en lo frívolo, pero que, en la incomprensión de estos tiempos, podrían ser amargamente talladas de inactuales, hasta de insolentes. No hay que dejarse engañar pos las apariencias (...) Tomar posesión del espacio, es el primer gesto de lo viviente, de los hombres $y$ de las bestias, de las plantas y de las nubes, es manifestación fundamental de equilibrio y duración. La primera prueba de existencia, es ocupar el espacio. (...) La arquitectura, la escultura y la pintura, son específicamente dependientes del espacio, ligadas a la necesidad de regular el espacio, cada una por medios apropiados. Lo que se dirá de esencial aquí es: que la clave de la emoción estética es una función espacial (Le Corbusier, 1946 [1998]:46).

El llamado que hizo Le Corbusier revalidó la idea de que la arquitectura moderna era un proyecto de mundo en el cual el hombre se desplegaba estableciendo vínculos con la realidad que lo rodeaba y construía su experiencia a través de la urdimbre de relaciones que se fundaban en la vivencia del espacio; en suma, era una apuesta por una existencia humana que propendía por superar la permanencia física inclinándose hacia la apropiación de la experiencia del habitar donde se tomaba posesión del territorio y el lugar era el espacio asible o lo que en palabras de Le Corbusier (1946/1998:48) sería: "la toma de posesión del espacio crea una armonía indiscutible, suelda la empresa humana a la tierra, y se corona con un alto acontecimiento plástico, arquitectural y urbano de alto alcance emotivo".

Sin duda, esta noción acerca de habitar el espacio nos remite a Heidegger y su reflexión en torno a la idea del espacio vivido que rechaza las posturas psicologistas que encierran el concepto de espacio exclusivamente en el sujeto que percibe, por un lado y, las de extremo realistas que dirigen su atención en la idea de espacio ligada fundamentalmente a la existencia de lo físico, por otro. Heidegger asume su postura desde la ontología que involucra al ser en el mundo a través de las relaciones que, como dijimos líneas arriba, se establecen en el habitar, pues es allí donde el hombre se realiza y se reafirma en el mundo; de ahí, que para Heidegger el habitar este previo al construir, dice Heidegger:

Lo que sea en su esencia construir edificios es algo sobre lo que no podemos preguntar ni siquiera de un modo suficiente, y no habremos de decidirlo de un modo adecuado a la cuestión, mientras no pensemos que todo construir es en sí un habitar. No habitamos porque hemos construido, sino que construimos y hemos 


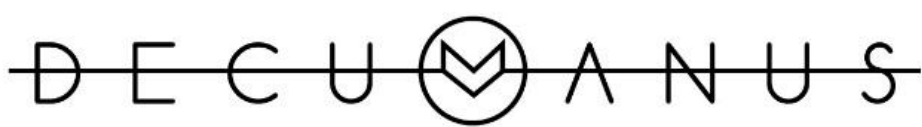

REVISTA INTERDISCIPLINARIA SOBRE ESTUDIOS URBANOS
Núm. 1 Vol. 1. Octubre 2015 - Octubre 2016

Instituto de Arquitectura, Diseño y Arte

Universidad Autónoma de Ciudad Juárez

ISSN: 2448-900X

construido en la medida que habitamos, es decir, en cuanto que somos los que habitan (1951/1994:2-3).

Esta noción de espacio, ligada a la capacidad humana de vincular su existencia a las posibilidades que el contexto le ofrece creando, fundamentalmente, espacios habitables y optando por convertir su experiencia en un conocimiento cualitativamente más elevado del que la mera experiencia física le pueda aportar, alcanzó una de sus expresiones más consistentes en un edificio particular: la capilla de Notre Dame du Haut en Ronchamp, Francia (Imágenes 12 y 13), más conocida simplemente como Ronchamp, un pequeño edificio de culto dedicado a la Virgen María realizado entre 1950 y 1954 que se sucedió a otro que fue destruido en la guerra y que encargarían a nuestro arquitecto un par de sacerdotes de una pequeña localidad bastante apartada de la capital francesa y próxima a la frontera nororiental con Suiza, y que, en buena medida, nos puede ayudar a ejemplificar la nueva apuesta por el espacio hecha por Le Corbusier en los años de la segunda posguerra, época en la que aún sostenía que "Yo no he experimentado el milagro de la fe, pero he vivido con frecuencia el milagro del espacio inefable" (Le Corbusier, 1998:47).

Ronchamp fue una respuesta única frente al contexto al aparecer sobre la zona más alta de una colina desde la cual se logra tener una visión de trescientos sesenta grados sobre el extenso Valle de Sanoa. El edificio, a diferencia de los otros ejemplos a los que hemos hecho mención hasta el momento, no se corresponde estrictamente con las geometrías primarias de las épocas precedentes sino que incorpora únicamente tres planos curvos que parten de una planta oblonga, casi trapezoidal, que sutilmente se elevan variando su inclinación hasta rematar en un plano de cubierta alabeada que asciende hacia el sur y hacia el oriente como abriéndose con este gesto hacia el paisaje incorporando, incluso, un altar exterior sobre la fachada oriental que se corresponde con un gemelo en el interior del pequeño templo para poder realizar el culto a los peregrinos en el momento que la capacidad interior se colme, pues es un edificio que logra albergar a no más de setenta personas, aproximadamente. Del mismo modo, sobre la fachada norte y la fachada occidental aparecen exentos en el exterior el campanario y la fuente, de manera que al llegar a la cima de la colina y al recorrer la exterioridad del edificio, se encuentran los elementos del templo que otrora estaban incorporados en su interior de manera que la vivencia de la experiencia litúrgica se hace desde el exterior hacia el interior y viceversa. 

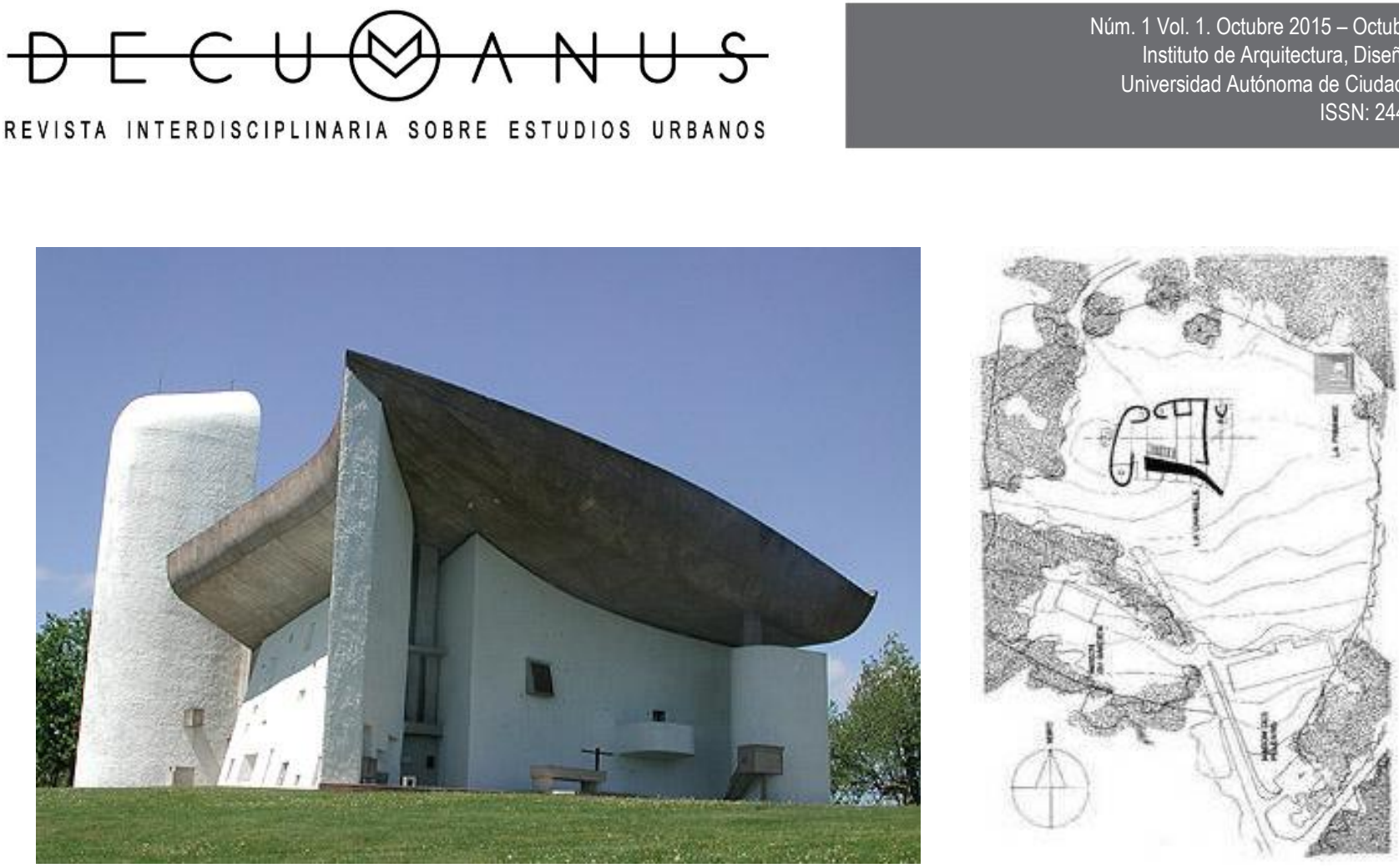

Imagen 12. Vista exterior desde el escorzo suroriental (www.galinsky.com)

Imagen 13. Planta General (www.albertoburgos.es)

La sinuosidad de las formas curvas que Le Corbusier había destinado, casi de manera exclusiva, a los elementos de circulación y a algunos muros en las terrazas-jardín, pero que poco se había permitido incorporar en los planos de fachada y cubierta habría de contener el "indecible" con lo que el edificio terminaría haciendo una apología a la colina sobre la cual se eleva, completando, estupendamente, la obra maestra, aparentemente inconclusa, de la naturaleza. Ronchamp así como los edificios de aquel tercer momento establecieron una relación particular, única e indisoluble con el territorio donde se localizaron, con lo que el territorio que otrora había sido simplemente espacio se cualificaba para convertirse en lugar.

Es importante reconocer en este sentido, que la capilla busca un diálogo respetuoso con su entorno incorporando dicho paisaje como contenedor ilimitado de su materialidad de tal modo que figura una armónica relación entre el místico interior creado (Imágenes 14, 15 y 16) y la vastedad del exterior natural (Imagen 17); esto, a diferencia de lo que sugiere el crítico de la arquitectura Josep María Montaner (1997), no se puede reconocer como un nuevo intento de Le Corbusier por imponer un orden absolutamente racionalizante al contexto natural, sino que se debe identificar como una apuesta por crear un diálogo con la multiplicidad de posibilidades que el entorno le entrega participando, así, de la creación de mundo a través de la arquitectura (Montaner, 1997). Sin lugar a dudas, en este planteamiento se subsume un intento por restablecer la intención fundante de la idea del espacio religioso de los primeros tiempos en las civilizaciones clásicas, época en la cual el edificio era el gran 


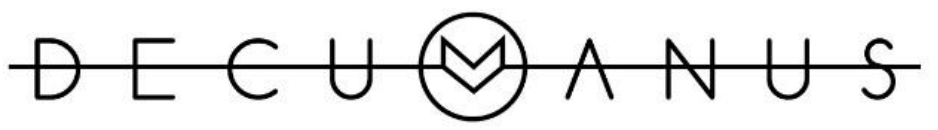

generador de un espacio sobrecogedor de reivindicación del ser humano frente a su dios, donde el contexto natural, incorporado al edificio, era una necesidad inmanente (Giedion, 1986).

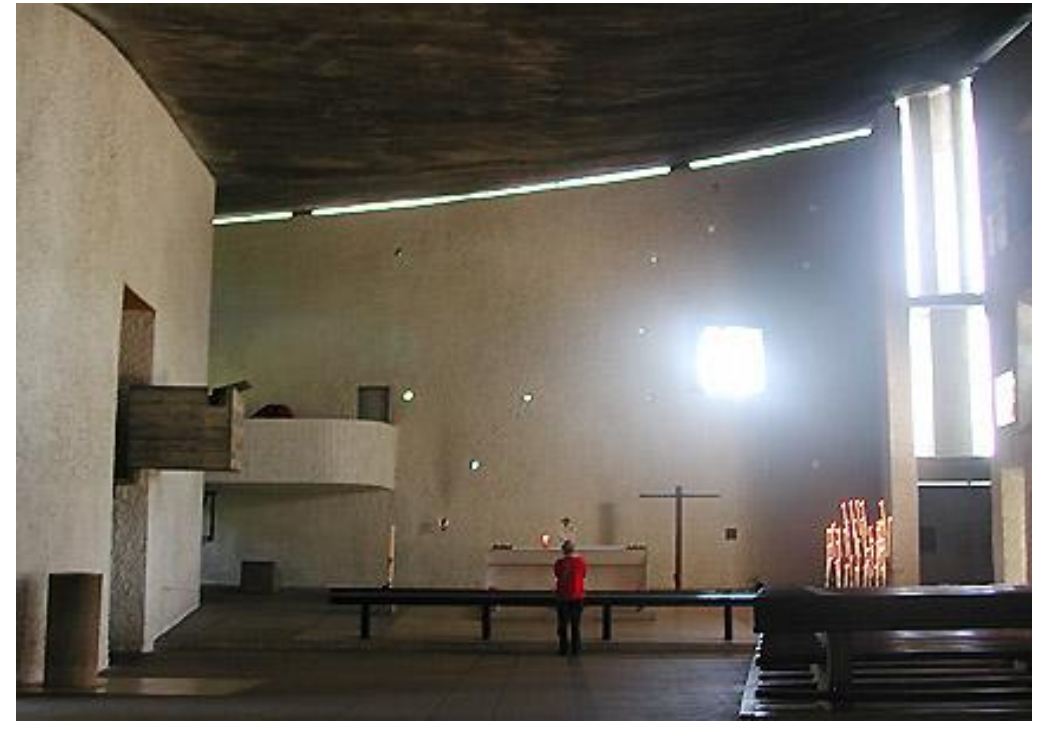

Imagen 14. Vista al altar de Ronchamp - Interior hacia el oriente (www.galinsky.com)

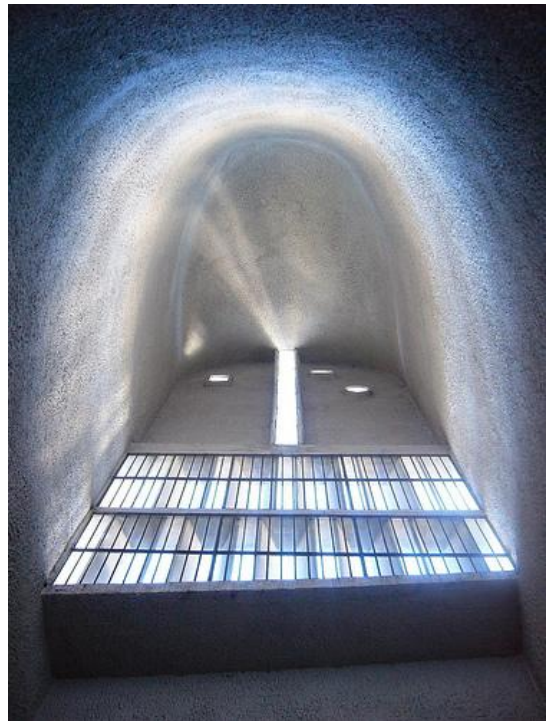

Imagen15. Interior de la Capilla Sur

(www.galinsky.com)

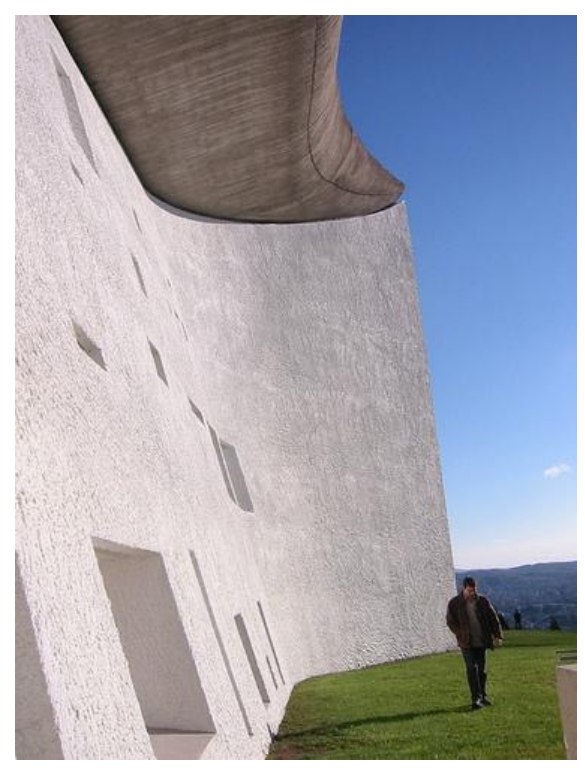

Imagen 16. Fachada sur (www.flickr.com)

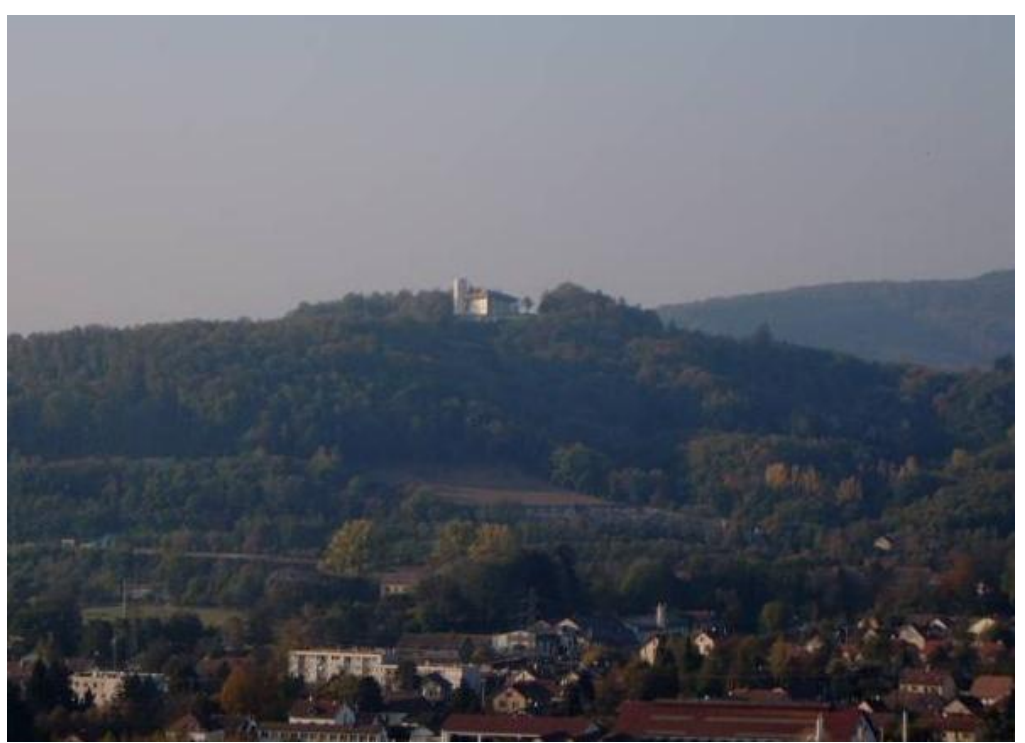

Imagen 17. Vista lejana de Ronchamp desde Sanoa (www.wikimedia.org)

La nueva arquitectura de la época de la segunda posguerra mantendría la utilización de los materiales que habían revolucionado el escenario arquitectónico e ingenieril de los primeros años del siglo XX; de manera magistral Le Corbusier lograría diluir lo que parecía indisoluble valiéndose del hormigón 


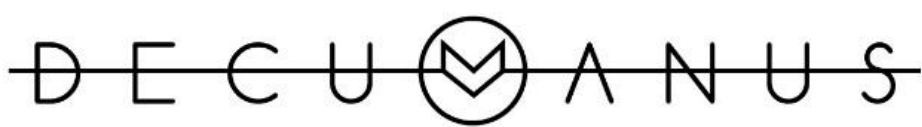

REVISTA INTERDISCIPLINARIA SOBRE ESTUDIOS URBANOS

armado como un aliado para lograr conseguir, en un edificio como Ronchamp, el nuevo espacio indecible con el que había soñado. Gracias a la utilización de ciertas aberturas, que podrían acercarse a la idea de muro inmaterial de la época del gótico donde se incorporaba el muro calado (Imagen 18), la fachada sur se horadaría de piso a techo con múltiples vanos de diferentes tamaños, permitiendo una relación visual entre el interior y el exterior donde el espectador era quien construía el vínculo de reciprocidad entre el espacio creado y el universo infinito (Imágenes 19, 20, 21 y 22).

Sobre la fachada oriental donde está el altar principal, se abría un amplio vano vertical acompañado de otro cuadrado que incorporaría la pequeña imagen de la Virgen a quien está dedicada la capilla siendo esta la fachada con más luz; las fachadas norte y occidental están casi cerradas por completo y únicamente permiten la entrada de luz sobre las pequeñas capillas de sus extremos; de otro lado, estaría el cascarón de la cubierta soportado en unas columnas que se entreveían en los vanos corridos que aparecían en el remate de dos de los tres planos de fachada produciendo la sensación de que la cubierta flotaba y, a su vez, permitirían la entrada de luz permanente desde el amanecer hasta el ocaso. De este modo el edificio es cambiante, la luz hace que la configuración interna del espacio creado cambie en la medida que afecta su posible percepción; mientras aceptemos que el hombre es de esencia abierta y su capacidad de configurar relaciones con esta realidad material es igualmente cambiante, entenderemos las razones que llevaron a Le Corbusier a superar todas las preocupaciones por una arquitectura meramente física y lo perfilaron hacia el horizonte de concebir edificios capaces de convertirse en imagen y proyección de la existencia humana. 


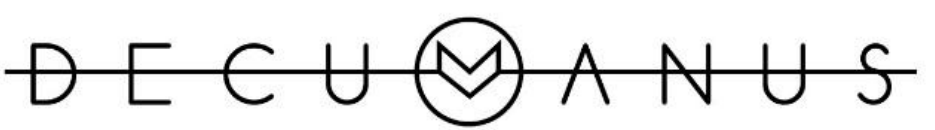

REVISTA INTERDISCIPLINARIA SOBRE ESTUDIOS URBANOS
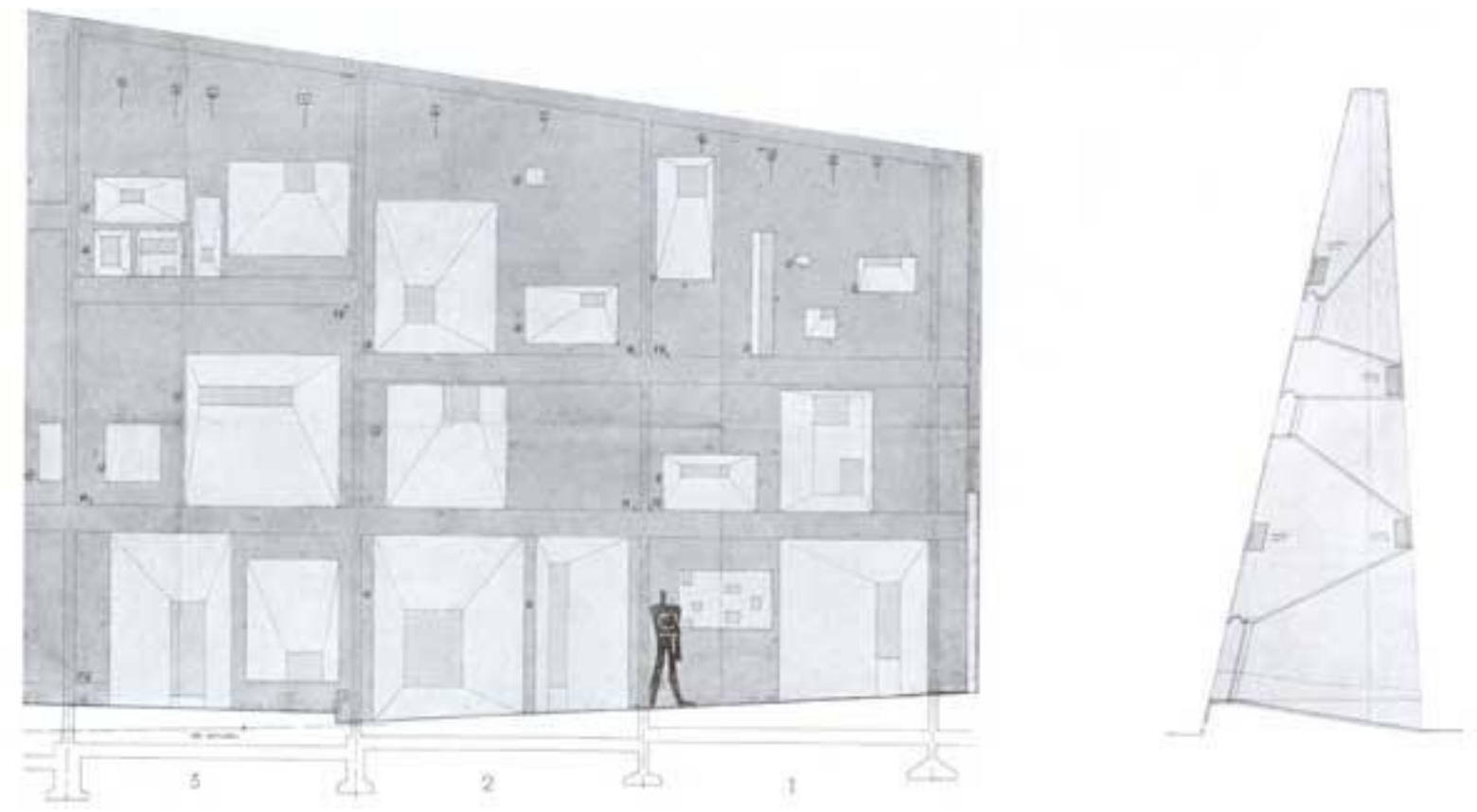

Imagen 18. Disposición de los vanos sobre la fachada sur de Ronchamp (www.wikimedia.org)

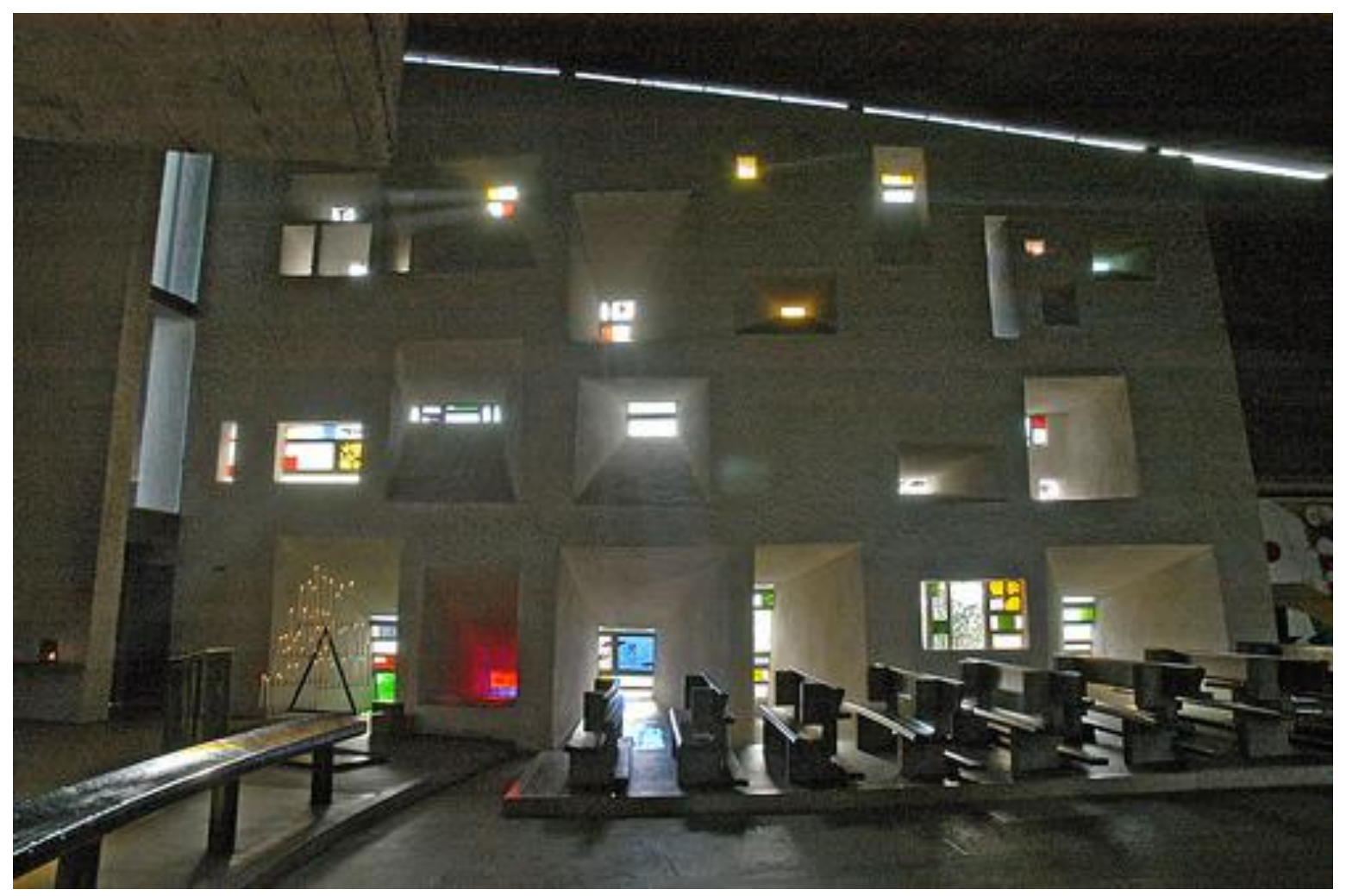

Imagen 19. Fachada Sur de Ronchamp - Interior (www.flickr.com) 


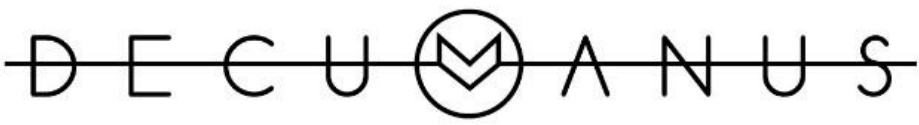

REVISTA INTERDISCIPLINARIA SOBRE ESTUDIOS URBANOS
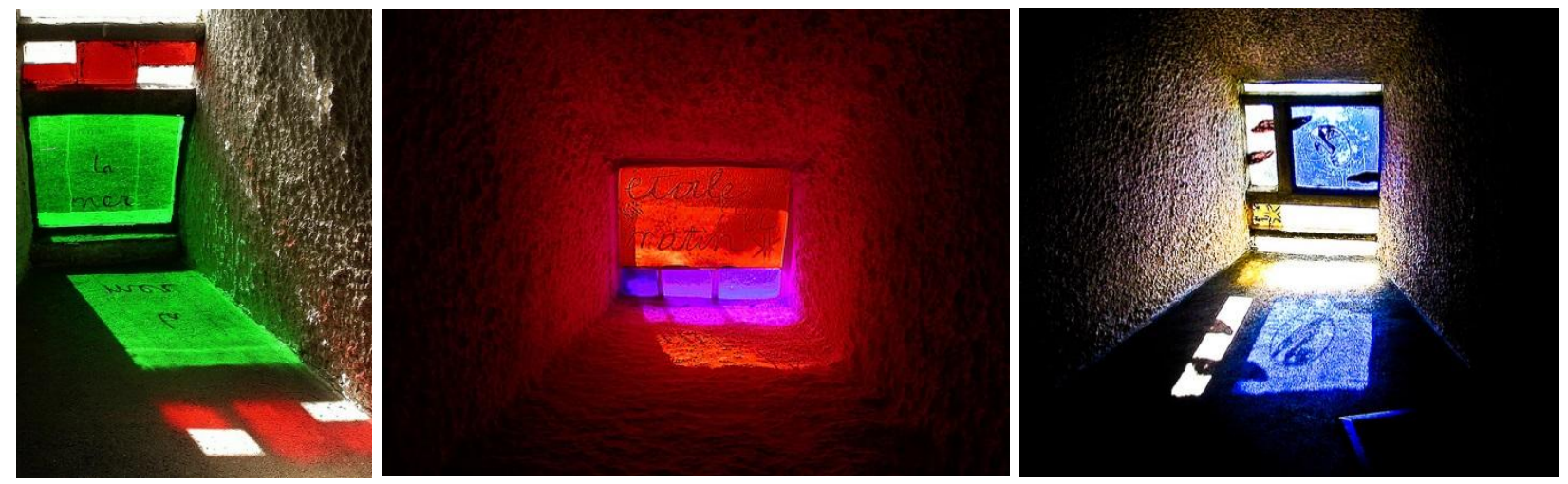

Imágenes 20 - 21 - 22. Detalles de las vidrieras de la Fachada Sur de Ronchamp - Interior (Todas las imágenes: www.flickr.com)

Con Ronchamp la noción de habitar tal y como la definió Heidegger y como la concibió Le Corbusier alcanzaría su sentido pleno al permitirle al sujeto que la vive crear relaciones de encuentro con la realidad física que lo rodea, realidad que se reinventa como espacio habitable, de manera que esa colina sobre el valle de Sanoa que otrora fuera simplemente una montaña, se convierte en un lugar único donde confluyen múltiples realidades dando sentido a otra nueva realidad cargada de significación. En consecuencia, el hombre queda definido con el ser que habita, es decir, como el ser único capaz de fundar relaciones cargadas de sentido con el contexto que lo rodea, razón de más para suponer que el problema de la arquitectura es un problema antropológico en cuanto da cuerpo material a las relaciones que fundan la existencia humana (Heidegger, 1994).

Ronchamp nos remite a la preocupación que mencionábamos al iniciar este apartado cuando hacíamos referencia a la noción de espacio después de la Teoría de la Relatividad de Einstein y que para la arquitectura puede entenderse como el anti-espacio o el espacio-tiempo, en correspondencia, insistimos, con la liquidación de la discontinuidad y el estaticismo de la idea tradicional de espacio sumado a la incorporación de la variable del movimiento que, para este tercer momento, pretende acompañar dicha dinámica. En este sentido, la nueva arquitectura de la segunda postguerra se recreó en la idea de habitar que, sin duda, tal y como lo entendía Heidegger, era creación de mundo donde el hombre vinculó el hecho material con un entorno que no se presentaba inhóspito sino lleno de posibilidades que permitiría brindar al hombre un escenario de posibilidades donde sustentar su existencia, indistintamente de las opciones que habría de elegir para habitar el mundo que había creado.

Es curioso decir ahora que Le Corbusier era ateo y que Ronchamp no se correspondía con algún tipo de recreación de la noción místico-religiosa que pudiera albergar en su interior por su 


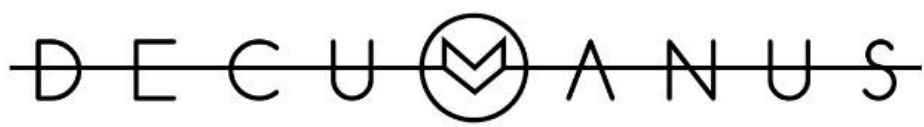

REVISTA INTERDISCIPLINARIA SOBRE ESTUDIOS URBANOS

memoria o tradición; más bien recordemos que él sentía profunda admiración por la arquitectura pagana, más particularmente por la arquitectura griega extraordinariamente representada con la Acrópolis de Atenas y, de manera especial, con el Partenón, edificio sobre el cual decía "no existe nada equivalente en la arquitectura de toda la tierra y de todos los tiempos. Es el momento más agudo en que un hombre, agitado por los más nobles pensamientos, los ha cristalizado en una plástica de luz y de sombra" (Le Corbusier, 1930[1998]:180) Ronchamp se elevaba sobre el valle de Sanoa como el Partenón lo hacía sobre la Acrópolis de Atenas, de manera que provocaba la experiencia espacial del espectador en la medida que este descubría el edificio en su ascenso a la cima de la montaña tras recorrer un largo camino serpenteante, tal y como lo hacía el templo dórico en mención tras recorrer el camino de la vía Panatenáica que se encumbraba hasta la Acrópolis para encontrarlo de escorzo luego de traspasar el umbral de los Propileos, logrando así entrever desde los diferentes ángulos del edificio su forma única de responder al entorno; incluso, el edificio debía recorrerse primero en su exterioridad para luego adentrarse en él y así comprender la correlación de los llenos y vacíos frente a lo que hay tras el muro mismo.

La verdad es que pocas veces los detractores de la modernidad lecorbusiana optaron por contrariar su obra partiendo de Ronchamp, tal vez fue por la sorpresa que les produjo que algunos de los militantes ortodoxos del Movimiento Moderno hubieran obrado como sus primeros opositores al señalar que Ronchamp era casi un regreso a la irracionalidad; sin embargo, a nuestro entender evitaron hacerlo, fundamentalmente, porque les fue más sencillo no dar la razón del hecho de que algunas arquitecturas y algunos arquitectos de la primera mitad del siglo XX lograron reconocer sus limitaciones y sólo por no renunciar al compromiso de crear un mejor mundo humano como fue el caso de Le Corbusier, aceptaron cargar con el lastre de sus desaciertos y recrear su proyecto mientras seguían el camino hacia una arquitectura. Aparentemente con Ronchamp aquellos detractores podrían haber sugerido que lo que Le Corbusier había criticado en los años de entreguerras de pronto salía a la luz y, finalmente, sus ojos podían ver; desde nuestra mirada Le Corbusier no abandonó jamás la racionalidad manifiesta de "Hacia una Arquitectura", más bien lo que hizo fue seguir utilizándola de manera consciente en la búsqueda de una experiencia cada vez más humana de la arquitectura.

Ahora bien, el arquitecto no puede desconocer que la relación que el hombre establece con el mundo a través de la arquitectura cambia y, por tanto, su trabajo ha de estar orientado a dar una respuesta acertada a dichas variaciones. Le Corbusier, por ejemplo, fue un claro exponente de tal búsqueda, en tanto, trató de crear un sistema de proporciones que optó por denominar el Modulor que fuera eco de la nueva relación que, en medio de la agitada modernidad del siglo XX, establecía el 


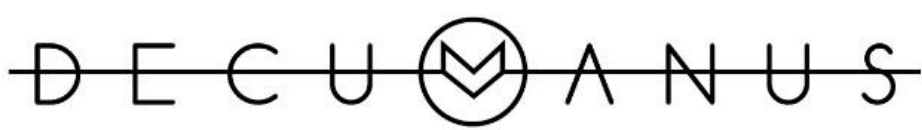

REVISTA INTERDISCIPLINARIA SOBRE ESTUDIOS URBANOS
Núm. 1 Vol. 1. Octubre 2015 - Octubre 2016

Instituto de Arquitectura, Diseño y Arte

Universidad Autónoma de Ciudad Juárez

ISSN: 2448-900X

hombre con el mundo. Esta relación, a pesar de haber sido descrita por el mismo Le Corbusier como un sistema que mediaba entre la matemática y la proporción humana, lo que realmente visibiliza es la apuesta por una nueva relación entre el ser corpóreo y el edificio meramente material con el hombre moderno y la nueva sensibilidad contemporánea. Decía Le Corbusier:

Las cifras del Modulor son medidas, y, por consiguiente, hechos en sí que tienen corporeidad; son efecto de una elección entre infinitos valores y además, tales medidas pertenecen a los números y tienen las virtudes de estos; pero los objetos que hay que construir y cuyas dimensiones determinan ellas, son, de cualquier modo, continentes de hombre o prolongaciones de hombre (1961:57).

La pregunta que quedaría por hacer ahora es ¿si la tarea del arquitecto consiste en la delimitación del espacio y, de ser así, de donde se infiere que el espacio en cuanto tal es algo dado y el arquitecto le da forma?, o ¿es la tarea del arquitecto la creación propiamente dicha del espacio? A nuestro entender, el arquitecto no parte de un espacio general, sino que es un creador de espacio de manera que configura ordenadamente los diferentes modos en que el espacio se cualifica articulando la imagen mental que del espacio arquitectónico se ha hecho en su cabeza y la materialización del espacio real a través del edificio que es el que será percibido a través de los sentidos. La verdadera arquitectura permitirá al hombre el desarrollo de su propio yo en unidad con los constructos creados por el arquitecto, es decir, la verdadera arquitectura tendrá, como fin último, permitir el habitar. En este sentido, el habitar es algo vivo, dinámico y cambiante que permite visualizar la manera en que se despliega el ser del hombre. La labor del arquitecto en las diferentes épocas consiste en mediar entre la imagen mental que los hombres tengan del mundo, en razón del sistema de valores que hayan establecido y la posible realización material de dicha imagen, es decir, de dicho proyecto de mundo, de ahí que debamos reconocer, digamos así, que la arquitectura no tiene como fin ocuparse simplemente del espacio sino, insistimos, de la idea de espacio que se nos presenta en permanente construcción en virtud del habitar.

\section{Reflexión final}

Cuando comenzamos este artículo nos propusimos dar a conocer la apuesta arquitectónica de quien se sigue considerando como el más polémico de los modernos; aquella labor sugerimos hacerla a través de sus manifiestos que, como bien descubrimos en el proceso investigativo hasta definir como un proyecto de mundo en tanto se correspondía con la apuesta de una civilización equitativa e igualitaria en un momento histórico particular que regresó a las manos humanas la posibilidad de erigir 


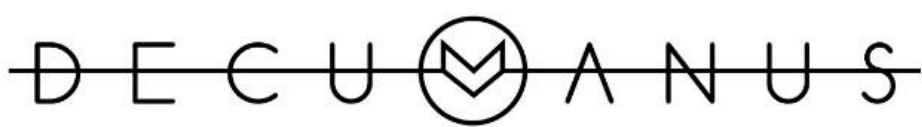

REVISTA INTERDISCIPLINARIA SOBRE ESTUDIOS URBANOS
Núm. 1 Vol. 1. Octubre 2015 - Octubre 2016

Instituto de Arquitectura, Diseño y Arte

Universidad Autónoma de Ciudad Juárez

ISSN: 2448-900X

su mundo libremente y a reconocer con ello la multiplicidad de formas de habitarlo. La labor emprendida esperaba desmitificar la idea de que la arquitectura moderna lecorbusiana se correspondía con el pensamiento maquínico de que la arquitectura se resumía en la mal entendida frase de Le Corbusier de la "máquina de habitar" y que mejor aún tenía que ver con la relación que el hombre establece con el universo, en tanto, logra instalarse en él a través de la arquitectura.

La voluntad colectiva que puso en manos del arquitecto moderno la facultad de hacer un nuevo mundo en el mundo, superaría las preocupaciones estéticas mismas, pues la arquitectura estaría llamada a mostrar, parafraseando a Otl Aicher, más que la belleza la profundidad óntica de las manifestaciones teóricas que subyacían en aquel mundo como proyecto cuya finalidad dirigía sus intereses a ser una condición posibilitante que superaba, en amplio margen, cualquier discusión de uso meramente práctico o instrumental, sin negar con ello que habría de cumplir irrestrictamente con aquella condición. En suma, lo que en el fondo ha subyacido en nuestras intenciones es traer a la luz lo que Le Corbusier tenía en la base de la creación de aquel nuevo paradigma arquitectónico en virtud de lo que parecía ser, para aquel entonces, la mejor manera de la establecer una naturaleza artificial como una posibilidad de mundo autónomo creado por la voluntad humana bajo la utopía de alcanzar con ello la construcción de un renovado universo cultural que redignificara su propia existencia a través de la respuesta dada a las necesidades básicas y fundamentales del hombre moderno y la sociedad europea en un momento histórico sin parangón alguno.

\section{Bibliografía}

Aicher, O. (1994). El mundo como proyecto. México D.F.: Gustavo Gili. (2001). Analógico y Digital. Barcelona: Gustavo Gili.

Argan, G. (1982). El concepto del espacio arquitectónico: desde el barroco hasta nuestros días. Buenos Aires: Nueva Visión.

Banham, R. (1985). Teoría y diseño en la primera era de la mágquina. Barcelona: Paidós.

Bollnow, F. (1969). Hombre y espacio. Barcelon: LAbor.

Collins, P. (1998). Changing Ideals in Modern Architecture (2 ${ }^{\underline{a}}$ ed.). Canadá: Mc Gill University Press.

Compagnon, A. (1993). Las cinco paradojas de la modernidad. Caracas: Monte Ávila Editores. 


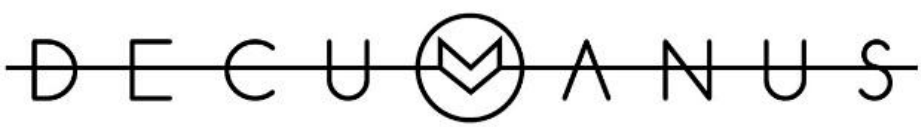

REVISTA INTERDISCIPLINARIA SOBRE ESTUDIOS URBANOS

Einstein, A. (2000). Mis ideas y opiniones. Madrid: Antoni Bosch.

Fleming, W. (1989). Arte, música e ideas. México D.F.: McGraw Hill.

Frampton, K. (1987). Historia crítica de la arquitectura moderna. Barcelona: Gustavo Gili.

Giedion, S. (1986). El presente eterno. Los comienzos de la arquitectura. Madrid: Alianza.

Heidegger, M. (1994). Construir, habitar, pensar. En M. Heidegger, Conferencias y artículos. Barcelona: Serbal.

Huse, N. (1986). Le Corbusier. Barcelona: Salvat.

Jeckns, C. (1980). Lenguaje de la arquitectura posmoderna. Barcelona: Gustavo Gili.

Kruft, H.-W. (1994). A History of Architectural Theory from Vitrivius to the Present. New York: Princeton Architectural Press.

Le Corbusier. (1930 [1998]). Hacia una arquitectura. Barcelon: Poseidón. . (1946[1998]). El espacio inefable. DC. Revista de cr'ticia arquitectónica (1), 46-55. . (1961). El Modulor. Ensayo sobre una medida armónica a la escala humana aplicable universalmente a la arquitectura y a la mecánica. Buenos Aires: Poseidón.

Lyotard, J. (1984). La Condición Postmoderna. Madrid: Cátedra. 